\title{
Time-Restricted Eating and Metabolic Syndrome: Current Status and Future Perspectives
}

\author{
Iwona Świątkiewicz ${ }^{1,2, *\left(\mathbb{D}, \text { Alina Woźniak }^{3}(\mathbb{D} \text { and Pam R. Taub }\right.}{ }^{2}$ \\ 1 Department of Cardiology and Internal Medicine, Collegium Medicum, Nicolaus Copernicus University, \\ 85-094 Bydgoszcz, Poland \\ 2 Division of Cardiovascular Medicine, University of California San Diego, La Jolla, CA 92037, USA; \\ ptaub@health.ucsd.edu \\ 3 Department of Medical Biology and Biochemistry, Collegium Medicum, Nicolaus Copernicus University, \\ 85-092 Bydgoszcz, Poland; alina-wozniak@wp.pl \\ * Correspondence: iwona.swiatkiewicz@gmail.com; Tel.: +1-858-249-1308
}

Citation: Świątkiewicz, I.; Woźniak, A.; Taub, P.R. Time-Restricted Eating and Metabolic Syndrome: Current Status and Future Perspectives. Nutrients 2021, 13, 221. https:// doi.org/10.3390/nu13010221

Received: 30 November 2020 Accepted: 11 January 2021 Published: 14 January 2021

Publisher's Note: MDPI stays neutral with regard to jurisdictional clai$\mathrm{ms}$ in published maps and institutional affiliations.

Copyright: (C) 2021 by the authors. Licensee MDPI, Basel, Switzerland. This article is an open access article distributed under the terms and conditions of the Creative Commons Attribution (CC BY) license (https:// creativecommons.org/licenses/by/ $4.0 /)$.
Abstract: Metabolic syndrome (MetS) occurs in $~ 30 \%$ of adults and is associated with increased risk of cardiovascular disease and diabetes mellitus. MetS reflects the clustering of individual cardiometabolic risk factors including central obesity, elevated fasting plasma glucose, dyslipidemia, and elevated blood pressure. Erratic eating patterns such as eating over a prolonged period per day and irregular meal timing are common in patients with MetS. Misalignment between daily rhythms of food intake and circadian timing system can contribute to circadian rhythm disruption which results in abnormal metabolic regulation and adversely impacts cardiometabolic health. Novel approaches which aim at restoring robust circadian rhythms through modification of timing and duration of daily eating represent a promising strategy for patients with MetS. Restricting eating period during a day (time-restricted eating, TRE) can aid in mitigating circadian disruption and improving cardiometabolic outcomes. Previous pilot TRE study of patients with MetS showed the feasibility of TRE and improvements in body weight and fat, abdominal obesity, atherogenic lipids, and blood pressure, which were observed despite no overt attempt to change diet quantity and quality or physical activity. The present article aims at giving an overview of TRE human studies of individuals with MetS or its components, summarizing current clinical evidence for improving cardiometabolic health through TRE intervention in these populations, and presenting future perspectives for an implementation of TRE to treat and prevent MetS. Previous TRE trials laid the groundwork and indicate a need for further clinical research including large-scale controlled trials to determine TRE efficacy for reducing long-term cardiometabolic risk, providing tools for sustained lifestyle changes and, ultimately, improving overall health in individuals with MetS.

Keywords: time-restricted eating; metabolic syndrome; abdominal obesity; hyperglycemia; dyslipidemia; inflammation; oxidative stress; cardiometabolic risk; circadian rhythm; eating pattern

\section{Introduction}

Metabolic syndrome (MetS) occurs in approximately $30 \%$ of adults and is associated with increased cardiometabolic morbidity and mortality [1-4]. The presence of MetS doubles the long-term risk of developing cardiovascular disease (CVD) and cardiovascular mortality, and is associated with a 5-fold increase in the risk of type 2 diabetes mellitus (T2DM) [2,3]. The MetS is characterized by multiple risk factors for CVD and T2DM including central obesity, elevated fasting plasma glucose (FPG), dyslipidemia, and elevated blood pressure (BP) [3,5]. In general, MetS reflects the clustering of individual cardiometabolic risk factors related to abdominal obesity and insulin resistance [2]. Once CVD or T2DM develops, the number of MetS components contributes to disease progression and patient outcome [3]. 
Erratic eating patterns such as eating over a prolonged period per day and eating more than three meals a day are common [6-11] and are associated with obesity, T2DM, MetS, and CVD [12-15]. It has been shown that over $50 \%$ of people eat during a period $>15$ h every day, only $\sim 10 \%$ of adults habitually maintain fasting of $\geq 12 \mathrm{~h}$ per day $[7,9,10]$. In an American population of patients with MetS, the eating window, defined as the time interval during a day in which $95 \%$ of all calorie-containing ingestion events occur, was

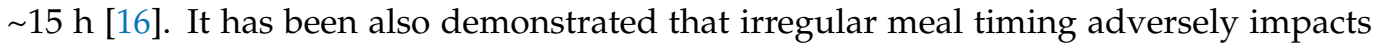
cardiometabolic health [14]. Misalignment between daily rhythms of food intake and circadian timing system can contribute to circadian rhythm disruption which results in abnormal metabolic regulation, disruption of metabolic homeostasis, and increased cardiometabolic risks [17-21].

Obesity, physical inactivity, and erratic dietary patterns are among the most important modifiable risk factors that contribute to the pathogenesis of MetS and its cardiometabolic outcomes $[2,22,23]$. Improving the diet and structured lifestyle interventions are currently the first line of treatment for MetS, and are critical to prevent disease progression [6,22-25]. However, due to poor patient adherence the effectiveness of interventions that address disturbed metabolic homeostasis through changes in quality and quantity of nutrition, increase in physical activity, and promotion of weight loss with low-calorie diets is low [25-27]. Moreover, these strategies are difficult to sustain long-term, so their efficacy at improving cardiometabolic risks in patients with MetS is limited.

Novel approaches which aim at mitigating circadian disruption through modifying timing and duration of daily food intake represent a promising strategy for patients with MetS [18,24,28-32]. Time-restricted eating (TRE) is a lifestyle intervention in which eating is restricted to a reduced, fixed number of hours per day, which supports an adequate fastening period $[10,12,18,30,33]$. The underlying hypothesis for the effectiveness of TRE in metabolic disorders is that imposing eating-fasting cycles will restore robust circadian rhythms and improve metabolic regulatory mechanisms, which can favorably impact cardiometabolic outcomes. Recently, several small-scale clinical studies employing TRE were performed in individuals with metabolic disorders [10,11,16,34-44]. A few recent reviews evaluated the metabolic effects of TRE in both animal and human studies; however, they were not focused exclusively on the populations with MetS [18,45-47].

The present article aims at giving an overview of the protocols and results of TRE clinical human studies of individuals with MetS or its components, summarizing current clinical evidence for improving cardiometabolic outcomes and overall health through TRE intervention in these populations, and presenting future perspectives for an implementation of TRE to prevent and treat MetS.

\section{Diagnostic Criteria of MetS and Its Components}

According to the International Diabetes Federation Joint Interim Statement criteria, MetS is defined in the presence of $\geq 3$ of the following 5 risk factors: increased waist circumference (population- and country-specific definitions should be used), elevated FPG ( $\geq 100 \mathrm{mg} / \mathrm{dL}$ or drug treatment of elevated glucose), elevated BP (systolic $\geq 130$ and/or diastolic $\geq 85 \mathrm{~mm} \mathrm{Hg}$ or antihypertensive drug treatment for diagnosed hypertension), hypertriglyceridemia ( $\geq 150 \mathrm{mg} / \mathrm{dL}$ or drug treatment for this lipid abnormality), and reduced high-density lipoprotein cholesterol (HDL-C) $(<40 \mathrm{mg} / \mathrm{dL}$ in males and $<50 \mathrm{mg} / \mathrm{dL}$ in females or drug treatment for this lipid abnormality) $[3,48]$. The cut-off values of increased waist circumference for males are $94 \mathrm{~cm}, 102 \mathrm{~cm}$, and $90 \mathrm{~cm}$ in European, US, and other populations including the Asian population, respectively $[3,48]$. For females, these values are $80 \mathrm{~cm}, 88 \mathrm{~cm}$, and $80 \mathrm{~cm}$, respectively. Most patients with T2DM will have the MetS by the proposed criteria $[3,48]$.

Overweight and obesity, typically defined as the body mass index (BMI) of $\geq 25 \mathrm{~kg} / \mathrm{m}^{2}$ and $\geq 30 \mathrm{~kg} / \mathrm{m}^{2}$, respectively, significantly increase the probability of metabolic disorders including MetS and are major risk factors for CVD and T2DM [1-3,49,50]. For the BMI, the optimal cut-off point for the identification of metabolic disorders in the European 
population is $27.2 \mathrm{~kg} / \mathrm{m}^{2}$ [51]. The waist circumference measurement is recommended for those with BMI of 25 to $34.9 \mathrm{~kg} / \mathrm{m}^{2}$ to provide additional information on CVD risk; however, if BMI is $>30 \mathrm{~kg} / \mathrm{m}^{2}$, central obesity can be assumed and waist circumference does not need to be measured [3,48]. However, owing to the need for screening of individuals with a metabolically obese normal weight, the measuring of waist circumference should be considered when BMI is $\geq 22.5 \mathrm{~kg} / \mathrm{m}^{2}$ in females and $\geq 23.8 \mathrm{~kg} / \mathrm{m}^{2}$ in males [50-52].

In the adult US population, the prevalence of overweight and obesity was reported as high as $71 \%$ and $40 \%$, respectively [2]. Overweight or obesity occur in $~ 83 \%, \sim 76 \%$, and $\sim 74 \%$ of subjects with T2DM, hypertension, and dyslipidemia, respectively [53]. Importantly, MetS was diagnosed in $\sim 33 \%$ of overweight and $\sim 65 \%$ of obese individuals [50]. The prevalence of elevated waist circumference indicating abdominal obesity, hypertriglyceridemia, elevated BP, and hyperglycemia in the adult US population were reported as $\sim 56 \%, \sim 24 \%, \sim 24 \%$, and $\sim 20 \%$, respectively [54]. In the Metabolic syndrome and Arteries REsearch (MARE) Consortium of 34,821 subjects with MetS, mostly from the European countries, two clusters of factors were observed in $12 \%$ and $13 \%$ of subjects; first, hypertriglyceridemia, elevated BP and increased waist circumference, and second, elevated FPG, elevated BP and increased waist circumference [1].

\section{Impact of Circadian Rhythms and Circadian Rhythm Disruption on Metabolic Homeostasis}

The central pathophysiological feature of MetS is a disruption in metabolic homeostasis with excess central adiposity followed by insulin resistance, impaired FPG and/or impaired glucose tolerance [5,55]. Other metabolic and neuroendocrine disorders such as reduced level of adiponectin, leptin resistance, aberrant ghrelin and resistin levels, and a deficiency of melatonin were also linked to obesity-related disorders including MetS [56-62]. In addition, low-grade inflammation and oxidative stress contribute to the pathophysiology of obesity, atherosclerosis, T2DM, and MetS [5,63-66]. Elevated C-reactive protein (CRP) levels, which are related to insulin resistance and MetS, are independent predictors of CVD events [63,67-71]. Oxidative stress is associated with adiposity, impaired insulin signaling pathways, insulin resistance, and increased risk of cardiometabolic diseases [64,72-74].

Circadian rhythms are a regulatory mechanism that maintains metabolic homeostasis and coordinates the processes of nutrition, physical activity, and sleep such that anabolic and catabolic pathways are active at different times of the $24 \mathrm{~h}$ day $[18,33,75-79]$. Systematic analyses of circadian gene expression in the mouse liver revealed a dominant role of eating pattern on daily rhythms in gene expression [76]. A daily rhythm in the eating-fasting cycle supports a robust rhythm in mRNAs and proteins, which regulate metabolic processes such as gluconeogenesis, glycolysis, protein synthesis, lipid synthesis and oxidation, and mitochondrial function $[18,33,76,78,80,81]$. For example, insulin sensitivity, $\beta$ cell responsiveness, the thermic effect of food, and fatty acids oxidation are all higher in humans in the morning than later during the day, which suggests that metabolism is optimized for food intake in the morning $[18,20,47,78,82]$. It has been demonstrated in human studies that eating in alignment with circadian rhythms, e.g., by increasing food intake at breakfast time and reducing it at dinnertime, can result in weight loss and improvements in glycemic control and lipid levels [81,83]. Metabolic homeostasis is also significantly influenced by circadian-related hormones such as cortisol, melatonin, adipokines, resistin, and ghrelin [56-62]. For example, melatonin regulates energy flow by influencing the intensity and circadian distribution of metabolic processes including the proper synthesis, secretion and action of insulin and, consequently, glucose homeostasis [18,56,57,60,78].

Misalignment between circadian timing system and daily rhythms of food intake or sleep-wake behavior as a result of genetic, environmental or behavioral factors can contribute to circadian rhythm disruption which adversely impacts metabolic homeostasis and cardiovascular function $[17,21,78,84-87]$. Circadian disruption results in abnormal constant activation or suppression of metabolic regulatory mechanisms, which can cause abnormal glucose metabolism with defective glucose tolerance and insulin resistance [17-20]. Circadian disruption was also shown to be associated with an increase of oxidative stress, 
activation of inflammation, as well as disordered regulation and aberrant secretion of circadian-related hormones $[17,59,60,73]$. A large body of epidemiologic and clinical evidence indicated that circadian disruption due to shift work, sleep deprivation, and erratic eating patterns is associated with an increased risk of MetS and its components, T2DM, and CVD $[13,77,82,88-92]$. For example, late-night caloric intake increased the risk of coronary heart disease by as much as 55\%, even after controlling for diet and lifestyle [13]. Therefore, lifestyle interventions that improve daily rhythms of behavior including eating pattern can favorably impact circadian rhythms and are expected to improve cardiometabolic health $[12,29,81]$.

\section{Effects of TRE in Animals and Healthy Humans}

A number of animal-based studies indicated that maintaining an appropriate daily rhythm of eating-fasting cycles sustains robust circadian rhythms, which improves cellular metabolism [80,93-97]. TRE is a circadian rhythm-reinforcing lifestyle which introduces a consistent period of $12-16 \mathrm{~h}$ fasting every day, which in various pathways mitigates circadian disruption and promotes improved metabolic homeostasis $[12,18,76]$. TRE restores normal levels and/or normal daily rhythms in several mRNAs, proteins, and metabolites that are implicated in metabolic homeostasis of glucose, lipids, redox, and mitochondria function, and regulates circulating adiponectin and leptin levels. TRE was shown to exert pleiotropic beneficial effects on multiple organ systems of mice (liver, muscle, white adipose tissue, brown adipose tissue, gut, and brain) [93-96] and insects (muscle, heart, brain) [97]. TRE had beneficial impact on mitochondrial structure and function which translates to improved physiology in animals, such as improved endurance and cardiac contractility $[93,94,97]$. In animal models, an implementation of TRE for $8-12 \mathrm{~h}$ per day prevented fatty liver, dyslipidemia, and glucose intolerance, as well as resulted in improvements in glycemic control, insulin levels, inflammation, body weight regulation, energy expenditure, motor coordination, cardiac contractility, sleep, and endurance level [12,18,80,93-97]. Beneficial effects of TRE were dose-dependent with better effects post $9 \mathrm{~h}$ protocol compared to 12 or $15 \mathrm{~h}[47,94]$. TRE reversed many aspects of MetS by decreasing body weight, adiposity, glucose intolerance, as well as cholesterol and triglycerides (TG) levels, and improving heart function. Importantly, TRE resulted in cardiometabolic benefits even when food intake and/or body weight was matched to the control group [93,95]. Thus, TRE can impart benefits irrespective of nutrition quantity and quality and seems to be both preventive and therapeutic for cardiometabolic diseases [18]. Therefore, there is a potential to adopt TRE for improving cardiometabolic health in humans with metabolic disorders including MetS [18,28,30].

Several small-scale TRE human studies were conducted in healthy individuals with normal weight, both young including subjects undergoing resistance training or recreationally active [98-102] and in middle aged and older adults [103-105]. These studies demonstrated that TRE is a feasible and well tolerated dietary strategy across the lifespan. Various beneficial effects of TRE, which were initially shown in animal studies, were demonstrated in healthy humans. TRE resulted in a decrease in energy intake $[98,101]$, body weight even without reducing energy intake [98,99], body fat [99,100,102,104], BP [99], blood glucose and TG [100], glucose tolerance [105], leptin and inflammatory markers [100], and hunger [105], as well as an increase in adiponectin and HDL-C $[99,100]$ and muscular strength and endurance capacity $[101,102,105]$. In healthy non-obese adults, TRE did not impact lean mass, muscular performance, bone density, and nutrient intake [100-102,105]. However, in several studies of healthy subjects, no significant impact of TRE was found on body weight [100,101], body fat [101], glucose and insulin levels [99,102], lipids [99,100,102], inflammatory markers [105], and cortisol pattern [99,102]. Moreover, healthy adults with normal weight not aligning TRE to the circadian rhythm (i.e., concentrating food intake to late afternoon or evening) exhibited worsened cardiometabolic outcomes such as elevated FPG and morning glucose intolerance [103]. Several review articles addressed TRE effects 
in healthy humans and indicated that this dietary strategy can be beneficial for subjects with cardiometabolic diseases including MetS [12,18,28,30,33,46,47,76].

\section{Characterization of TRE Trials in Humans with MetS or Its Components}

Several small-scale TRE human studies were performed in individuals with metabolic disorders such as MetS or its components [10,11,16,34-44]. The protocols of these studies differed in terms of objectives, study design, inclusion criteria, population, sample size, duration of TRE eating window and intervention, diet prescription, and methods of recording food intake. In addition to the objectives associated with a feasibility of TRE intervention, TRE studies aimed at evaluating changes in cardiometabolic biomarkers. The main characteristics of TRE trials which were conducted in humans with MetS or its components are shown in Table 1.

\subsection{Study Design}

TRE human studies of populations with metabolic disorders were designed either as randomized controlled trials [11,34,35,42-44] or, more frequently, single-arm studies including one group of participants with pre-post intervention design [10,16,35,37-41]. A lack of control group in the single-arm studies is a potential limitation implying that the results of these studies should be interpreted with caution. Several studies were pilot trials which aimed primarily at testing a feasibility of TRE intervention $[10,11,34,38,41]$.

Most TRE studies were based on small sample size, usually less than 20 participants in single-arm studies (except for the study of Kesztyüs et al. [41] which involved 40 subjects). On average, 30 participants were included in randomized controlled trials with 6-20 participants in each arm. The study of Lowe et al. [44] included 116 participants but only 50 of them participated in an in-person cohort (with 25 participants in each arm) which was subject to cardiometabolic outcomes analyses.

\subsection{Inclusion Criteria and Participants}

Populations with metabolic disorders included young $[10,39,40,43]$, midlife $[11,16,34,36,37,41,42,44]$ and older subjects [38]. The inclusion criteria comprised an increased BMI indicating overweight or obesity [10,11,34-36,38-40,42-44], diagnosed MetS or $\geq 1$ of its components such as increased waist circumference [16,37,41], and the diagnosis of prediabetes or T2DM or high risk of developing T2DM [35,37,41]. To qualify as having prediabetes in the study of Sutton et al. [35], participants needed to exhibit both elevated glycated hemoglobin ( $\mathrm{HbA} 1 \mathrm{c}$ ) and impaired glucose tolerance based on an oral glucose tolerance test. In the study of Hutchinson et al. [37], the high risk of T2DM was determined based on the Australian Type 2 Diabetes Risk Assessment Tool (AUSDRISK) score including the risk factors such as age, sex, ethnicity, parental history of diabetes, history of high blood glucose, use of antihypertensive medications, physical inactivity, and obesity defined as an increased BMI and/or waist circumference.

To our knowledge, only the study of Wilkinson et al. [16] enrolled exclusively patients with diagnosed MetS. In that study, eligible participants had to satisfy $\geq 3$ of MetS criteria and self-reported dietary intake of $\geq 14 \mathrm{~h}$ per day, regular daytime schedule of activity, and self-reported habitual sleep duration of $>6.5 \mathrm{~h}$. The exclusion criteria included diagnosis of diabetes, shift work, history of major adverse cardiac events, active medical conditions, history of eating disorder or bariatric surgery, participation in the weight-management program, special diet for other reasons, substance abuse, depression, sleep apnea, and treatment with antidepressants, medication affecting glucose metabolism or appetite, or immunosuppression. Patients in that study had central obesity and elevated TG, FPG and $\mathrm{HbA1c}$. The majority of patients $(84 \%)$ received pharmacotherapy for elevated BP and dyslipidemia such as antihypertensive medications in $79 \%$ and statins in $63 \%$ of patients. 
Table 1. Main characteristics of time-restricted eating trials in humans with metabolic syndrome or its components.

\begin{tabular}{|c|c|c|c|c|c|}
\hline Reference and Study Design & Inclusion Criteria & Participants & TRE Duration and EW & Meal Timing During TRE & Primary Outcome \\
\hline $\begin{array}{l}\text { Gill and Panda [10] } \\
\text { One group (pre-post design), } \\
\text { pilot feasibility study }\end{array}$ & $\begin{array}{l}\text { Healthy adults } \\
\mathrm{BMI}>25 \mathrm{~kg} / \mathrm{m}^{2} \\
\mathrm{EW} \geq 14 \mathrm{~h}\end{array}$ & $\begin{array}{c}n=8(5 \mathrm{M}, 3 \mathrm{~F}) \\
\text { Overweight/obese } \\
\text { EW } 14.8 \mathrm{~h} \\
\text { Age } 34.4 \pm 2.9 \mathrm{y}(\mathrm{M}) \\
36.3 \pm 4.3 \mathrm{y}(\mathrm{F})\end{array}$ & $\begin{array}{l}16 \text { weeks } \\
\text { EW } 10-12 \text { h }\end{array}$ & Self-selected EW & Change in body weight \\
\hline $\begin{array}{l}\text { Antoni et al. [34] } \\
\text { Randomized controlled trial, } \\
\text { pilot feasibility study }\end{array}$ & $\begin{array}{l}\text { Healthy adults } \\
\text { BMI } 20-39 \mathrm{~kg} / \mathrm{m}^{2}\end{array}$ & $\begin{array}{c}n=13(12 \mathrm{~F}, 1 \mathrm{M}) \\
\text { Overweight/obese } \\
\text { TRE: } n=7(6 \mathrm{~F}, 1 \mathrm{M}) \\
\text { Age } 47 \pm 3 \mathrm{y} \\
\text { Control: } n=6(\mathrm{~F}) \\
\text { Age } 45 \pm 4 \mathrm{y}\end{array}$ & $\begin{array}{c}10 \text { weeks } \\
\text { EW } 8 \text { h } 37 \text { min } \pm 22 \text { min }\end{array}$ & $\begin{array}{l}\text { TRE: breakfast delayed and } \\
\text { dinner advanced by } 1.5 \mathrm{~h} \\
\text { each } \\
\text { Control: } \mathrm{AL}\end{array}$ & $\begin{array}{l}\text { Feasibility of TRE in } \\
\text { reducing EW }\end{array}$ \\
\hline $\begin{array}{l}\text { Sutton et al. [35] } \\
\text { Crossover }\end{array}$ & $\begin{array}{c}\text { Males } \\
\text { Age } 35-70 \mathrm{y} \\
\text { BMI } 20-39 \mathrm{~kg} / \mathrm{m}^{2} \\
\text { Prediabetes (based on HbA1c } \\
\text { and OGTT) }\end{array}$ & $\begin{array}{l}\quad n=8(\mathrm{M}) \\
\text { Overweight/obese } \\
\text { and prediabetic } \\
\text { Age } 56 \pm 9 \mathrm{y}\end{array}$ & $\begin{array}{c}5 \text { weeks } \\
\text { in each condition } \\
\text { EW } 6 \text { or } 12 \mathrm{~h}\end{array}$ & $\begin{array}{l}\text { eTRE: } 8 \text { a.m. }-2 \text { p.m. } \\
\text { (dinner before } 3 \text { p.m.) } \\
\text { Control: } 8 \text { a.m. }-8 \text { p.m. } \\
3 \text { meals provided and } \\
\text { matched across arms }\end{array}$ & $\begin{array}{l}\text { Changes in glucose tolerance, } \\
\text { postprandial insulin, and } \\
\text { insulin sensitivity }\end{array}$ \\
\hline $\begin{array}{c}\text { Gabel et al. }[36,106,107] \\
\text { Matched historical controls, } \\
\text { pilot study }\end{array}$ & $\begin{array}{c}\text { Age } 25-65 \mathrm{y} \\
\text { BMI } 30-45 \mathrm{~kg} / \mathrm{m}^{2} \\
\text { Sedentary to lightly active }\end{array}$ & $\begin{array}{c}n=46(41 \mathrm{~F}, 5 \mathrm{M}) \\
\text { Obese } \\
\text { TRE: } n=23(20 \mathrm{~F}, 3 \mathrm{M}) \\
\text { Age } 50 \pm 2 \mathrm{y} \\
\text { Control: } n=23(21 \mathrm{~F}, 2 \mathrm{M}) \\
\text { Age } 48 \pm 2 \mathrm{y}\end{array}$ & $\begin{array}{l}12 \text { weeks } \\
\text { EW } 8 \mathrm{~h}\end{array}$ & $\begin{array}{l}\text { TRE: } 10 \text { a.m.-6 p.m. } \\
\text { Control: AL }\end{array}$ & Change in body weight \\
\hline $\begin{array}{l}\text { Hutchison et al. [37] } \\
\text { Crossover }\end{array}$ & $\begin{array}{c}\text { Age } 30-70 \mathrm{y} \\
W C \geq 102 \mathrm{~cm} \\
\text { High risk of T2DM }\end{array}$ & $\begin{array}{c}n=15(\mathrm{M}) \\
\text { Obese (abdominal } \\
\text { obesity) } \\
\text { Age } 55 \pm 3 \text { y }\end{array}$ & $\begin{array}{c}7 \text { days in each condition } \\
\text { EW } 9 \mathrm{~h}\end{array}$ & $\begin{array}{l}\text { eTRE: } 8 \text { a.m. }-5 \text { p.m. } \\
\text { dTRE: } 12 \text { p.m. }-9 \text { p.m. }\end{array}$ & $\begin{array}{l}\text { Glucose response to a } \\
\text { mixed-nutrient meal in } \\
\text { men at risk for T2DM }\end{array}$ \\
\hline $\begin{array}{l}\text { Anton et al. [38] } \\
\text { One group (pre-post design), } \\
\text { pilot feasibility study }\end{array}$ & $\begin{array}{c}\text { Age } \geq 65 \mathrm{y} \\
\text { BMI } 25-40 \mathrm{~kg} / \mathrm{m}^{2} \\
\text { Sedentary }\end{array}$ & $\begin{array}{c}n=10(6 \mathrm{~F}, 4 \mathrm{M}) \\
\text { Overweight/obese } \\
\text { Age } \geq 65 \mathrm{y}\end{array}$ & $\begin{array}{l}4 \text { weeks } \\
\text { EW } 8 \mathrm{~h}\end{array}$ & Self-selected EW & $\begin{array}{l}\text { Feasibility and safety of TRE } \\
\text { in overweight, older adults }\end{array}$ \\
\hline $\begin{array}{l}\text { Jamshed et al. [39], } \\
\text { Ravussin et al. [40] } \\
\text { Crossover }\end{array}$ & $\begin{array}{l}\text { Healthy adults } \\
\text { Age 20-45 y } \\
\text { BMI } 25-35 \mathrm{~kg} / \mathrm{m}^{2}\end{array}$ & $\begin{array}{c}n=11(4 \mathrm{~F}, 7 \mathrm{M}) \\
\text { Overweight/obese } \\
\text { Age } 32 \pm 7 \mathrm{y}\end{array}$ & $\begin{array}{l}4 \text { days } \\
\text { EW } 6 \text { or } 12 \mathrm{~h}\end{array}$ & $\begin{array}{l}\text { eTRE: } 8 \text { a.m. }-2 \text { p.m. } \\
\text { Control: } 8 \text { a.m.- } 8 \text { p.m. } \\
3 \text { meals provided and } \\
\text { matched across arms }\end{array}$ & $\begin{array}{l}\text { Change in energy } \\
\text { expenditure }\end{array}$ \\
\hline
\end{tabular}


Table 1. Cont.

\begin{tabular}{|c|c|c|c|c|c|}
\hline Reference and Study Design & Inclusion Criteria & Participants & TRE Duration and EW & Meal Timing During TRE & Primary Outcome \\
\hline $\begin{array}{l}\text { Kesztyüs et al. [41] } \\
\text { One group (pre-post design), } \\
\text { pilot feasibility study }\end{array}$ & $\begin{array}{l}\text { One or more components of } \\
\text { MetS, including T2DM non } \\
\text { requiring insulin }\end{array}$ & $\begin{array}{c}n=40(31 \mathrm{~F}, 9 \mathrm{M}) \\
\text { Abdominal obesity } \\
\text { Age } 49.1 \pm 12.4 \mathrm{y}\end{array}$ & $\begin{array}{l}12 \text { weeks } \\
\text { EW 8-9 h }\end{array}$ & Self-selected EW & $\begin{array}{l}\text { Adherence to TRE } \\
\text { intervention (proportion of } \\
\text { days with fasting } \\
\geq 15 \mathrm{~h} \text { ) }\end{array}$ \\
\hline $\begin{array}{l}\text { Wilkinson et al. [16] } \\
\text { One group (pre-post design), } \\
\text { pilot study }\end{array}$ & $\begin{array}{c}\text { Diagnosed MetS }(\geq 3 \\
\text { components) } \\
\text { EW } \geq 14 \mathrm{~h}\end{array}$ & $\begin{array}{l}n=19(6 \mathrm{~F}, 13 \mathrm{M}) \\
\text { Obese with MetS } \\
\text { EW } 15.1 \pm 1.1 \mathrm{~h} \\
\text { Age } 59 \pm 11.1 \mathrm{y}\end{array}$ & $\begin{array}{l}12 \text { weeks } \\
\text { EW } 10 \mathrm{~h}\end{array}$ & Self-selected EW & $\begin{array}{l}\text { Change in mean blood } \\
\text { glucose (CGM) }\end{array}$ \\
\hline $\begin{array}{l}\text { Chow et al. [11] } \\
\text { Randomized controlled trial, } \\
\text { feasibility study }\end{array}$ & $\begin{array}{c}\text { Age } 18-65 \mathrm{y} \\
\mathrm{BMI} \geq 25 \mathrm{~kg} / \mathrm{m}^{2} \\
\mathrm{EW} \geq 14 \mathrm{~h}\end{array}$ & $\begin{array}{c}n=20(17 \mathrm{~F}, 3 \mathrm{M}) \\
\text { Overweight/obese } \\
\text { EW } 15.2 \pm 0.7 \mathrm{~h} \\
\text { TRE: } n=11(9 \mathrm{~F}, 2 \mathrm{M}) \\
\text { Age } 46.5 \pm 12.4 \mathrm{y} \\
\text { Control: } \\
n=9(8 \mathrm{~F}, 1 \mathrm{M}) \\
\text { Age } 44.2 \pm 12.3 \mathrm{y}\end{array}$ & $\begin{array}{l}12 \text { weeks } \\
\text { EW } 8 \mathrm{~h}\end{array}$ & $\begin{array}{l}\text { TRE: } \\
\text { Self-selected EW } \\
\text { Control: } \\
\text { AL }\end{array}$ & Change in body weight \\
\hline $\begin{array}{l}\text { Cienfuegos et al. [42] } \\
\text { Randomized controlled trial }\end{array}$ & $\begin{array}{c}\text { Age } 18-65 \mathrm{y} \\
\text { BMI } 30-49.9 \mathrm{~kg} / \mathrm{m}^{2} \\
\text { Sedentary or moderately } \\
\text { active }\end{array}$ & $\begin{array}{c}n=58(53 \mathrm{~F}, 5 \mathrm{M}) \\
\text { Obese } \\
\text { 4-h TRE: } \\
n=19(17 \mathrm{~F}, 2 \mathrm{M}) \\
\text { Age } 47 \pm 2 \mathrm{y} \\
\text { 6-h TRE: } \\
n=20(19 \mathrm{~F}, 1 \mathrm{M}) \\
\text { Age } 47 \pm 3 \mathrm{y} \\
\text { Control: } \\
n=19(17 \mathrm{~F}, 2 \mathrm{M}) \\
\text { Age } 45 \pm 2 \mathrm{y}\end{array}$ & $\begin{array}{c}8 \text { weeks } \\
\text { EW } 4 \text { or } 6 h\end{array}$ & $\begin{array}{l}\text { 4-h TRE: } 3 \text { p.m.-7 p.m. } \\
\text { 6-h TRE: } 1 \text { p.m.-7 p.m. } \\
\text { Control: AL }\end{array}$ & Change in body weight \\
\hline $\begin{array}{l}\text { Parr et al. [43] } \\
\text { Randomized controlled } \\
\text { crossover trial }\end{array}$ & $\begin{array}{c}\text { Males } \\
\text { Age } 30-45 \text { y } \\
\text { BMI 27-35 kg/m² } \\
\text { Sedentary lifestyle }\end{array}$ & $\begin{array}{c}n=11(\mathrm{M}) \\
\text { Overweight/obese } \\
\text { Age } 38 \pm 5 \mathrm{y} \\
\text { Group 1: } n=6 \\
\text { Group 2: } n=5\end{array}$ & $\begin{array}{l}5 \text { days } \\
\text { EW } 8 \mathrm{~h}\end{array}$ & $\begin{array}{l}\text { TRE: } 10 \text { a.m.-6 p.m. } \\
\text { Control: } 7 \text { a.m. }-10 \text { p.m. } \\
\text { Isoenergetic diet protocols }\end{array}$ & $\begin{array}{l}\text { Circadian blood profiles of } \\
\text { glucose and insulin }\end{array}$ \\
\hline
\end{tabular}


Table 1. Cont.

\begin{tabular}{|c|c|c|c|c|c|}
\hline Reference and Study Design & Inclusion Criteria & Participants & TRE Duration and EW & Meal Timing During TRE & Primary Outcome \\
\hline $\begin{array}{c}\text { Lowe [44] } \\
\text { Randomized controlled trial }\end{array}$ & $\begin{array}{c}\text { Age } 18-64 \text { y } \\
\text { BMI } 27-43 \text { kg/m² }\end{array}$ & $\begin{array}{c}n=116(46 \mathrm{~F}, 70 \mathrm{M}) \\
\text { Overweight/obese } \\
\text { Age } 46.5 \pm 10.5 \mathrm{y} \\
\text { In-person TRE group: } \\
n=25(12 \mathrm{~F}, 13 \mathrm{M}) \\
\text { Age } 43.3 \pm 11.8 \mathrm{y}\end{array}$ & $\begin{array}{l}12 \text { weeks } \\
\text { EW } 8 \mathrm{~h}\end{array}$ & $\begin{array}{c}\text { TRE: } 12 \text { p.m. }-8 \text { p.m. } \\
\text { CMT (consistent meal } \\
\text { timing): } \\
3 \text { structured meals per day }\end{array}$ & Change in body weight \\
\hline
\end{tabular}

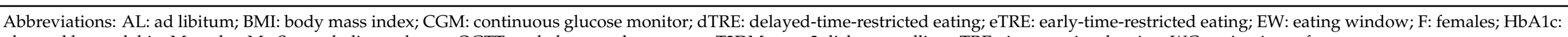
glycated hemoglobin; M: males; MetS: metabolic syndrome; OGTT: oral glucose tolerance test; T2DM: type 2 diabetes mellitus; TRE: time-restricted eating; WC: waist circumference. 
Several TRE human studies involved individuals with the presence of one or more components of MetS [11,35-38,42-44]. The typical multifactorial clusters of MetS components were as follows: increased waist circumference, elevated FPG and elevated BP $[37,38]$ as well as BMI $>30 \mathrm{~kg} / \mathrm{m}^{2}$ (indicating central obesity) accompanied with elevated FPG [35], elevated BP [11,42] or decreased HDL-C [36]. Participants in other TRE studies had either BMI $>30 \mathrm{~kg} / \mathrm{m}^{2}$ indicating central obesity $[10,39,40,43,44]$ or increased waist circumference [41]. Importantly, most patients (63\%) with abdominal obesity in the study of Kesztyüs et al. [41] received antihypertensive medications but only one patient was treated by statin. In addition, a few TRE studies of subjects with metabolic disorders comprised erratic eating pattern (mostly defined as habitually eating over a period $\geq 14 \mathrm{~h}$ per day) as an inclusion criterion $[10,11,16]$.

\subsection{TRE Window and Duration of Intervention}

The protocols of published TRE studies defined an eating window, i.e., a number of hours per day when food can be taken, to vary from as long as $12 \mathrm{~h}[10,35,39,40]$ to as short as $4 \mathrm{~h}[42]$ with the mean of $8-10 \mathrm{~h}$ in the majority of trials [11,34,36,38,41,43,44]. As a result, TRE intervention introduced a consistent period of fasting every day which could vary from 12 to $20 \mathrm{~h}$. The effects of TRE interventions with different eating windows (e.g., 4 vs. $6 \mathrm{~h}$ and 6 vs. $12 \mathrm{~h}$ ) were evaluated through direct comparisons between subgroups with different eating windows [42] or the use of a crossover study design [35,39,40,43]. In several studies, the start and end of the TRE eating window in the day was self-selected by participants $[10,11,16,38,41]$. In most studies, however, the start and end time of the eating window was imposed by the study protocol [35-37,39,40,42-44]. Also, the effects of early TRE, i.e., eating early in the day $[10,35,36,39,40]$ and delayed TRE, i.e., with a phase delay to late hours in the day $[37,44]$ were evaluated.

The designs of TRE studies included a different length of intervention period varying from short-term intervention of 4 days $[39,40]$ to long-term intervention of 16 weeks with the follow-up period up to 1 year [10]. The most frequent duration of TRE intervention was in the range of $8-12$ weeks $[11,16,34,36,41,42,44]$.

\subsection{TRE Intervention}

During TRE intervention, study participants were asked to restrict their food intake daily to a number of hours a day which was defined as an eating window and to fast for the remaining hours. They were also instructed to start the TRE intervention by selecting an eating window that best suits their lifestyle based on his/her baseline eating pattern or the start and end time of eating during a day were defined in the study protocols. For example, in the study of Wilkinson et al. [16] including patients with MetS, the 10-h TRE eating window had to be between 7 a.m. and 9 p.m., with the last meal (including non-water beverage) consumed at least $2 \mathrm{~h}$ prior to the typical bedtime. In this study, the 10-h interval was entered in a smartphone application, so participants could visualize their chosen daily eating window and consume all meals within this interval.

In several TRE studies of individuals with metabolic disorders, TRE was the only intervention, and participants were not instructed to change their habits regarding the quality, quantity, or caloric content of their diet; however, a meeting with a dietitian in-person for behavioral nutritional counseling was included in some protocols [10,16,34,38,41]. In some studies, special diet prescriptions were implemented, such as meals were provided with matched nutrients $[35,39,40,43]$, or ad libitum nutrition was recommended but within TRE eating window $[10,11,16,34,36,44]$. Specifically, in the trial of Sutton et al. [35], the obese and prediabetic male participants undergoing TRE intervention were required to eat only food provided by study staff, were fed enough food to maintain their weight, and ate all meals while being monitored by study staff. This protocol allowed testing of whether TRE has cardiometabolic benefits in the absence of weight loss.

In addition, in most TRE studies, participants with metabolic disorders were not instructed to change their habits regarding physical activity during TRE 
intervention [10,16,34,35,38-41]. However, in some studies, physical activity control was conducted using actigraphy devices or mobile phone applications [11,16,36,37,43,44].

\subsection{Use of the MyCircadianClock Application}

The myCircadianClock application (mCC app) for a smartphone is the validated HIPPA (Health Insurance Portability and Accountability Act) compliant method that was developed at the Salk Institute for Biological Studies (La Jolla, CA, USA) for recording food intake and monitoring adherence to TRE intervention in real time $[10,11,16]$. The server side of the app is designed to run multiple independent clinical studies with individual customization allowing study-specific customization by the investigator and user-specific customizations by participants. The mCC app serves as an electronic food, activity, and sleep diary [10]. In studies which used mCC app, participants were asked to record all food intake, physical activity, and sleep quantity/quality every day during TRE intervention $[10,11,16]$. Data from the app can be used to assess participant adherence, eating window, calorie intake, physical activity, and sleep. The adherence to mCC app use is high, mainly due to the simplicity of logging food metadata by making photo of food item or entering the name of food from the list.

\subsection{Calorie Intake Assessment}

In TRE studies using the mCC app, the food intake data (photo and/or annotation entries) were downloaded from the server-side of the app and dietary analyses were performed by a registered dietitian to calculate the overall calorie intake and estimate calories from macronutrient component, usually by using the Caloric King database [11,16]. Also, dietary records were used by TRE studies with ad libitum intake to document energy intake [36] or no food records were applied [44].

It is known that participants with obesity underreport energy intake by $20-40 \%$ when using food diaries [108] and self-reporting of adherence by patients is generally not accurate [109]. Implementing mobile apps to assess caloric intake in real-time seems to be more accurate than assessing it by self-report food records. It was shown that the falsenegative rate (i.e., food consumed but not logged) using the mCC app is $~ 10 \%$ [10]. Controlling unlogged dietary events is challenging, and the ideal control which is expensive and difficult in humans would involve direct observation of all dietary events [35]. However, such a strategy is unlikely to provide sustainable approach for long-term TRE intervention.

\subsection{Use of Continuous Glucose Monitor}

In several TRE studies, a continuous glucose monitor (CGM) was used for an evaluation of glucose metabolism $[11,16,37,39,40,43]$. CGM measures interstitial fluid glucose every $15 \mathrm{~min}$, using a subcutaneous sensor. CGM estimates blood glucose levels with high accuracy that correlates with those obtained from either venous or capillary blood. By using CGM, mean daily glucose level, post-prandial glucose response, mean amplitude of glycemic excursion, continuous overall net glycemic action, and the glycemic variability index can be calculated. CGM can also be used to track adherence to TRE intervention.

\subsection{Physical Activity and Sleep Assessment}

Actigraphy devices such as actiwatches or pedometers were used in several TRE studies to assess a level of physical activity and the duration, quality, and timing of sleep $[10,11,16,36-38,43,44]$. Sleep was also analyzed by mCC app and questionnaires such as the Pittsburgh Sleep Quality Index questionnaire [16,36].

\subsection{Body Composition Analysis}

The body composition measurements were usually performed using bioelectrical impedance technology or, less frequently, dual-energy X-ray absorptiometry (DXA) that is more accurate $[11,16,36,44]$. Bioelectrical impedance-measured percentage body fat and 
visceral fat, and greater muscle mass percentage, or DXA-measured fat mass, lean mass, or visceral fat were evaluated.

\subsection{Primary Outcomes}

The primary outcomes of TRE human clinical studies of individuals with metabolic disorders are depicted in Table 1. In general, they included the measures associated with an adherence and safety of TRE intervention, as well as post-TRE changes in cardiometabolic outcomes such as body weight, fat mass percentage, FPG, mean daily glucose levels obtained by CGM, glucose tolerance, postprandial insulin, insulin sensitivity, circadian blood profiles of glucose and insulin, and energy expenditure.

\section{Major Findings of TRE Trials in Humans with MetS or Its Components}

Major findings of TRE trials in humans with MetS or its components are displayed in Table 2.

Table 2. Major findings of time-restricted eating trials in humans with metabolic syndrome or its components.

\begin{tabular}{|c|c|c|}
\hline Reference and Study Design & MetS Components & Results of TRE \\
\hline $\begin{array}{l}\text { Gill and Panda [10] } \\
\text { One group (pre-post design), pilot } \\
\text { feasibility study }\end{array}$ & Mean BMI > $30 \mathrm{~kg} / \mathrm{m}^{2}$ & $\begin{array}{c}\downarrow \text { Body weight } \\
\downarrow \text { Hunger at night } \\
\uparrow \text { Morning and overall energy levels and sleep } \\
\text { satisfaction } \\
\downarrow \text { Energy intake }\end{array}$ \\
\hline $\begin{array}{l}\text { Antoni et al. [34] } \\
\text { Randomized controlled trial, pilot } \\
\text { feasibility study }\end{array}$ & BMI $29 \pm 2 \mathrm{~kg} / \mathrm{m}^{2}$ & $\begin{array}{c}\leftrightarrow \text { Body weight } \\
\downarrow \text { Body fat } \\
\downarrow \text { FPG } \\
\leftrightarrow \text { Fasting insulin, lipids } \\
\downarrow \text { Energy intake } \\
\downarrow \text { EW by } \sim 4.5 \mathrm{~h}\end{array}$ \\
\hline $\begin{array}{l}\text { Sutton et al. [35] } \\
\text { Crossover }\end{array}$ & $\begin{array}{c}\mathrm{BMI} 32 \pm 4 \mathrm{~kg} / \mathrm{m}^{2} \\
\mathrm{FPG} 102 \pm 9 \mathrm{mg} / \mathrm{dL}\end{array}$ & $\begin{array}{c}\qquad \leftrightarrow \text { Body weight } \\
\qquad \begin{array}{c}\text { Insulin sensitivity, } \beta \text {-cell function, TG } \\
\leftrightarrow \text { FPG, lipids, TNF- } \alpha, \text { IL-6 }\end{array} \\
\begin{array}{c}\downarrow \mathrm{BP}, \text { fasting and postprandial insulin, evening appetite, } \\
\text { oxidative stress }\end{array} \\
\text { Adherence to TRE was } 98 \% \text { (rigorously controlled trial) }\end{array}$ \\
\hline $\begin{array}{l}\text { Gabel et al. [36,106,107] } \\
\text { Matched historical controls, pilot } \\
\text { study }\end{array}$ & $\begin{array}{c}\mathrm{BMI} \geq 30 \mathrm{~kg} / \mathrm{m}^{2} \\
\mathrm{HDL}-\mathrm{C} 48 \pm 2 \mathrm{mg} / \mathrm{dL}\end{array}$ & $\begin{array}{c}\downarrow \text { Body weight } \\
\leftrightarrow \text { Body fat, FPG, fasting insulin, insulin resistance, } \\
\text { lipids, homocysteine, sleep quality/duration } \\
\downarrow \\
\downarrow \text { Energy intake } \\
\downarrow \text { Systolic BP }\end{array}$ \\
\hline $\begin{array}{l}\text { Hutchison et al. [37] } \\
\text { Crossover }\end{array}$ & $\begin{array}{l}\text { WC } 115 \pm 2 \mathrm{~cm} \\
\text { BP } 141 \pm 3 / 87 \pm 2 \mathrm{mmHg} \\
\text { FPG } 105 \pm 2 \mathrm{mg} / \mathrm{dL}\end{array}$ & $\begin{array}{c}\downarrow \text { Body weight } \\
\leftrightarrow \text { Body fat, FPG } \\
\downarrow \text { Mean fasting glucose (CGM) in eTRE } \\
\uparrow \text { Glucose tolerance } \\
\downarrow \text { Fasting TG, hunger }\end{array}$ \\
\hline $\begin{array}{l}\text { Anton et al. [38] } \\
\text { One group (pre-post design), pilot } \\
\text { feasibility study }\end{array}$ & $\begin{array}{c}\text { WC } 109 \pm 13 \mathrm{~cm} \\
\text { BP } 146 \pm 16 / 78 \pm 12 \mathrm{mmHg} \\
\text { FPG } 106 \pm 28 \mathrm{mg} / \mathrm{dL} \\
\text { BMI } 34 \pm 3 \mathrm{~kg} / \mathrm{m}^{2}\end{array}$ & $\begin{array}{c}\downarrow \text { Body weight } \\
\leftrightarrow \text { Blood glucose, WC, physical and cognitive function } \\
\uparrow \text { Quality of life } \\
\text { Adherence to TRE was } 84 \%\end{array}$ \\
\hline $\begin{array}{l}\text { Jamshed et al. [39] } \\
\text { Ravussin et al. [40] } \\
\text { Crossover }\end{array}$ & BMI $30 \pm 3 \mathrm{~kg} / \mathrm{m}^{2}$ & $\begin{array}{c}\downarrow \text { Mean } 24 \text { h glucose and glycemic excursions (CGM) } \\
\downarrow \text { Morning FPG, insulin and HOMA-IR; mean and } \\
\text { morning ghrelin, mean appetite } \\
\uparrow \text { Morning ketones, TC, LDL-C and HDL-C; metabolic } \\
\text { flexibility, fullness, fat oxidation } \\
\leftrightarrow \text { Energy expenditure } \\
\text { Altered cortisol patterns and circadian clock genes } \\
\text { expression related to aging, stress, autophagy, } \\
\text { oxidative stress }\end{array}$ \\
\hline
\end{tabular}


Table 2. Cont.

\begin{tabular}{|c|c|c|}
\hline Reference and Study Design & MetS Components & Results of TRE \\
\hline $\begin{array}{l}\text { Kesztyüs et al. [41] } \\
\text { One group (pre-post design), pilot } \\
\text { feasibility study }\end{array}$ & $\mathrm{WC} 107 \pm 13 \mathrm{~cm}$ & $\begin{array}{c}\downarrow \text { Body weight } \\
\downarrow \text { WC } \\
\downarrow \text { HbA1c } \\
\leftrightarrow \text { Lipids } \\
\text { Adherence to TRE was } 86 \%\end{array}$ \\
\hline $\begin{array}{l}\text { Wilkinson et al. [16] } \\
\text { One group (pre-post design), } \\
\text { pilot study }\end{array}$ & $\begin{array}{l}\text { Diagnosed MetS } \\
\text { WC } 109 \pm 11 \mathrm{~cm} \\
\text { FPG } 107 \pm 15 \mathrm{mg} / \mathrm{dL} \\
\text { TG } 161 \pm 87 \mathrm{mg} / \mathrm{dL} \\
\text { HDL-C } 47 \pm 13 \mathrm{mg} / \mathrm{dL} \\
\text { BMI } 30 \pm 5 \mathrm{~kg} / \mathrm{m}^{2}\end{array}$ & $\begin{array}{c}\downarrow \text { Body weight } \\
\downarrow \text { WC } \\
\downarrow \text { Body fat } \\
\leftrightarrow \text { Mean glucose (CGM), } \\
\text { HPG, fasting insulin, HOMA-IR, } \\
\text { HbA1c, HDL-C, TG, sleep quality } \\
\downarrow \text { TC, } \text { LDL-C, non-HDL-C } \\
\downarrow \text { Energy intake } \\
\downarrow \text { BP }\end{array}$ \\
\hline $\begin{array}{l}\text { Chow et al. [11] } \\
\text { Randomized controlled trial, } \\
\text { feasibility study }\end{array}$ & $\begin{array}{c}\text { BMI } 34 \pm 8 \mathrm{~kg} / \mathrm{m}^{2} \\
\mathrm{BP} 132 \pm 13 / 85 \pm 4 \mathrm{mmHg}\end{array}$ & $\begin{array}{c}\downarrow \text { Body weight } \\
\downarrow \text { Visceral fat mass, lean mass } \\
\downarrow \text { Fasting glucose (CGM), TG } \\
\leftrightarrow \text { Mean glucose (CGM), glucose tolerance, HbA1c, } \\
\text { lipids } \\
\text { No significant differences in changes of fasting glucose } \\
\text { and TG between TRE and non-TRE groups }\end{array}$ \\
\hline $\begin{array}{l}\text { Cienfuegos et al. [42] } \\
\text { Randomized controlled trial }\end{array}$ & $\begin{array}{c}\text { BMI } 36 \pm 1 \mathrm{~kg} / \mathrm{m}^{2} \\
\text { BP } 135 \pm 5 / 88 \pm 2 \mathrm{mmHg}\end{array}$ & $\begin{array}{l}\downarrow \text { Body weight } \\
\quad \downarrow \text { Fat mass } \\
\downarrow \text { Energy intake } \\
\downarrow \text { Insulin resistance } \\
\downarrow \text { Oxidative stress } \\
\quad \leftrightarrow \text { TNF- } \alpha, \text { IL-6 }\end{array}$ \\
\hline $\begin{array}{l}\text { Parr et al. [43] } \\
\text { Randomized controlled } \\
\text { crossover trial }\end{array}$ & $\mathrm{BMI} 32 \pm 2 \mathrm{~kg} / \mathrm{m}^{2}$ & $\begin{array}{c}\leftrightarrow \text { Peak and waking glucose, AUC } 24 \text { h glucose (CGM) } \\
\text { and insulin } \\
\downarrow \text { AUC nocturnal glucose (CGM) } \\
\uparrow \text { Feeling of well-being, TG }\end{array}$ \\
\hline $\begin{array}{c}\text { Lowe [44] } \\
\text { Randomized controlled trial }\end{array}$ & $\mathrm{BMI} 31 \pm 5 \mathrm{~kg} / \mathrm{m}^{2}$ & $\begin{array}{c}\downarrow \text { Body weight, lean mass, energy expenditure, diastolic } \\
\text { BP } \\
\leftrightarrow \text { Fat mass, FPG, fasting insulin, HOMA-IR, HbA1c, } \\
\text { lipids, systolic BP } \\
\text { No significant differences in changes of outcomes } \\
\text { between TRE and non-TRE groups }\end{array}$ \\
\hline
\end{tabular}

Abbreviations: AUC: area under the curve; BMI: body mass index; BP: blood pressure; CGM: continuous glucose monitor; dTRE: delayed-time-restricted eating; eTRE: early-time-restricted eating; EW: eating window; HbA1c: glycated hemoglobin; HDL-C: high-density lipoprotein cholesterol; HOMA-IR: homeostatic model assessment for insulin resistance; IL-6: interleukin-6; LDL-C: low-density lipoprotein cholesterol; MetS: metabolic syndrome; OGTT: Oral Glucose Tolerance Test; T2DM: type 2 diabetes mellitus; TC: total cholesterol; TG: triglycerides; TNF- $\alpha$ : tumor necrosis factor- $\alpha$; TRE: time-restricted eating; WC: waist circumference; $\uparrow:$ increased levels; $\downarrow$ : decreased levels; $\leftrightarrow$ : no difference.

\subsection{Adherence to TRE Intervention}

Based on mCC app logging, surveys through the custom mobile study app, or food diaries records, it has been demonstrated that the adherence to TRE intervention is high $[11,16,36,41,44]$. The adherence to TRE, defined as the proportion of days in which the TRE eating window was achieved during the whole TRE intervention period, was shown to be as high as $\sim 83-86 \%[11,16,36,41,44]$ and $98 \%$ of participants were adherent to required meal times when following early TRE while under rigorous control [35]. In addition, $\sim 63 \%$ of patients with MetS were still to some degree adherent to TRE at 16 months after completing the intervention despite they were not advised to continue TRE beyond the intervention period [16]. Self-selecting of TRE eating window seems to facilitate maintaining an adherence to TRE intervention long term [16]. 


\subsection{Eating Pattern}

Eating window duration significantly declined (on average by one-third) during TRE intervention and participants were able to maintain a shortened daily eating window for an extended period of time during TRE interventions lasting 12-16 weeks [10,11,16,36,41] and even up to 16 months $[10,16]$. In the pilot study of an American population with MetS, TRE resulted in shortening daily eating window from $\sim 15 \mathrm{~h}$ to $\sim 10 \mathrm{~h}$ with nightly fasting of $\sim 14 \mathrm{~h}$ during the 12-week period [16]. In addition, that eating pattern was achieved by delaying and advancing in meal timing rather than skipping meals and regularity in timing of meals was increased in that study. Also, in the study of Chow et al. [11] of obese adults, allowing unrestricted intake within an 8-h TRE resulted in a decrease in the number of eating occasions of $\sim 20 \%$.

\subsection{Body Weight, Waist Circumference, and Body Composition}

Several TRE studies of individuals with metabolic disorders focused on changes in body weight $[10,11,36,42,44]$. Typically, $8-16$ weeks of TRE with various eating windows of $4-10 \mathrm{~h}$ resulted in weight loss by $\sim 3-4 \%$ in overweight or obese subjects both young [10] and older $[11,36,38,42]$, prediabetic or diabetic subjects with abdominal obesity $[37,41]$, and patients with diagnosed MetS [16]. Importantly, 4-h and 6-h TRE produced comparable reduction in body weight by $\sim 3 \%$ in obese adults compared to controls [42]. Also, a reduction in BMI by $\sim 3 \%$ was observed post-TRE in patients with MetS [16]. The postTRE weight reduction of $3 \%$ in patients with MetS is comparable to the effects of calorie restriction combined with exercise in studies of subjects with glucose intolerance $[110,111]$. However, no significant changes in BP or lipids were reported in these studies in contrast to the results of Wilkinson et al. [16]. In the study of Lowe et al. [44], a significant decrease in weight was observed in the TRE group albeit to smaller extent than in other TRE studies. However, the change was not significant compared to the control group. It should be noted that most participants in that study self-reported their weight changes using a Bluetooth weighing scale that was linked to a custom app. In addition, no tools such as mCC app were used to monitor adherence. These factors could be a limitation of the study results. No change of body weight was observed after 10 weeks of $8 \mathrm{~h}$ TRE in overweight individuals despite a decrease in adiposity [34]. In the study of Sutton et al. [35], a lack of reduction in body weight post-TRE intervention in obese and prediabetic subjects was intentional and resulted from the special diet prescription which aimed at maintaining weight.

A decrease in body fat (percentage and mass) by $3-4 \%$ was observed post TRE in obese participants who exhibited weight loss [11,41,42], in patients with MetS independently of change in weight [16], and in overweight subjects without weight loss [34]. In addition, a reduction in visceral fat (up to $\sim 11 \%$ of DXA-measured fat mass in obese midlife subjects) and a decrease in waist circumference $(\sim 3-4 \%)$ were also observed post TRE in patients with MetS and abdominal obesity $[11,16,41]$. A decrease in waist circumference in patients with MetS correlated with change in body weight and eating window [16]. Moreover, greater restriction of the eating window was associated with greater loss of DXA-measured fat mass and visceral fat [11]. However, in a few other TRE studies of obese midlife sedentary subjects and obese individuals with high risk of T2DM, no change in body fat was found despite a decrease in body weight [36,37].

A decrease in body weight may account for some beneficial effects of TRE on cardiometabolic outcomes. However, in the study of patients with MetS, eating interval or weight did not account for all changes in cardiometabolic health [16]. In the study of Sutton et al. [35], post-TRE metabolic benefits were observed in the absence of weight loss.

Although lean mass was maintained post-TRE in healthy subjects with normal weight including those undergoing regular resistance training or recreational activity [100-102,105], a significant loss of lean mass was observed in obese midlife subjects [11,44]. It would be of interest to address the question as to whether TRE leads to preferential loss of lean (versus fat) mass and whether this effect is offset by changes in protein content or timing of protein consumption [44]. Also, it would be important to explore a potential risk of post-TRE 
muscle loss in elderly populations, especially that no measurements of body composition were made in the TRE study of overweight/obese individuals of age $\geq 65$ years, in which weight loss was observed [38].

\subsection{Calorie Intake}

A decrease in calorie intake by $\sim 9-20 \%$ was reported in TRE studies of overweight or obese individuals including patients with MetS despite no recommendations to change the diet quantity and quality during the intervention $[10,11,16,34,36,42]$. In obese adults without overt metabolic disease, energy intake was reduced by as much as $20 \%$ without calorie counting, partly due to a decrease in consumption of alcoholic beverages and late-night snacks [10,36]. Importantly, it was observed that 4-h and 6-h TRE produced comparable decrease in energy intake (by $\sim 550 \mathrm{kcal} /$ day) without calorie counting in obese adults compared to controls [42]. Importantly, diet quality did not change post-TRE in that study.

A decrease in energy intake may account for some beneficial effects of TRE on body weight and metabolic outcomes. However, in the study of Sutton et al. [35], which was a strictly controlled crossover feeding trial, post-TRE metabolic benefits were observed in the absence of calorie restriction and weight loss.

In some TRE studies, unintentional reduction in energy intake concurrent with a truncated TRE eating window was observed, which suggests that implementation of TRE without caloric reduction is difficult to achieve in humans due to spontaneous energy restriction during the study period $[16,36]$.

\subsection{Glucose Metabolism}

A decrease in mean glucose obtained from CGM was reported post-TRE in obese but otherwise healthy young adults [39,40] and obese subjects with high risk of T2DM [37], as well as FPG and fasting glucose obtained by CGM in overweight and obese midlife adults $[11,34]$. However, the reported changes in fasting glucose obtained by CGM were not significant when compared to non-TRE group in the study of Chow et al. [11]. TRE improved glucose tolerance in obese men with prediabetes with or without weight loss [35,37]. Both early and delayed TRE produced similar improvements in glucose tolerance; however, only early TRE significantly reduced fasting glucose obtained by CGM in obese men with high risk of T2DM [37]. Sutton et al. [35] showed that limiting food intake prior to 3 p.m. (early TRE) is beneficial for glycemic control in obese and prediabetic men, independent of weight change and reducing caloric intake. In that study, early TRE improved insulin sensitivity, insulin resistance, $\beta$-cell function, and decreased postprandial insulin, however, did not result in a change in FPG. Importantly, the reductions in insulin levels were the largest in participants with worse baseline hyperinsulinemia and persisted long term after completing TRE intervention. In addition, insulin and insulin resistance were improved in a few other TRE studies of overweight or obese subjects [34,36,42]. The $4 \mathrm{~h}$ and $6 \mathrm{~h}$ TRE produced similar reductions in insulin resistance in obese individuals [42]. When baseline FPG and HbA1c were elevated, TRE also resulted in improvements of glycemic control such as lowering $\mathrm{HbA} 1 \mathrm{c}$ by $\sim 4 \%$ in subjects with abdominal obesity and patients with MetS [16,41]. In addition, TRE improved nocturnal glycemic control in men with overweight or obesity [43]. It has been postulated that prolonged fasting during TRE intervention may improve glycemic control by the metabolic switch, which occurs when changing from fed to fasted state [30]. The metabolic switch induces hepatocyte production of ketone bodies, increasing insulin sensitivity and decreasing fat accumulation.

However, some TRE studies of individuals with metabolic disorders showed that some glycemic measures remain unchanged $[11,35,36,38,42-44]$. No significant improvements in average glucose obtained by CGM, FPG, and insulin resistance were observed in patients with MetS [16]. Importantly, however, moderate changes in the desirable direction of FPG, fasting insulin and $\mathrm{HbA1c}$ were reported post-TRE in patients with MetS [16]. This 
suggests that patients with more impaired glucose metabolism may benefit more from TRE compared to lower-risk individuals.

\subsection{Lipid Metabolism}

In the pilot study of patients with MetS, TRE led to significant reduction of atherogenic lipids such as total cholesterol ( 7\%), low-density lipoprotein cholesterol (LDL-C) ( 11\%) and non-high-density lipoprotein cholesterol levels $(\sim 9 \%)$, and a favorable trend towards reduction was found for TG and LDL-C particle number [16]. These changes in cholesterol levels cannot be explained solely by weight loss as a decrease of $5 \%$ of body weight was shown to result in a 3-5\% reduction in LDL-C, which is lower than the post-TRE level [112]. In the study of Wilkinson et al. [16], a 3\% weight loss was accompanied by $11 \%$ reduction in LDL-C. A decrease in TG was also observed post-TRE in obese subjects including prediabetic men [11,37]. In the study of Chow et al. [11], however, the changes were not significant when compared to the non-TRE group.

However, the observed effects of TRE on plasma lipids were highly variable and usually unchanged in other studies of overweight or obese subjects, including individuals with abdominal obesity, T2DM, and prediabetes [11,35-37,41,42,44]. Importantly, early TRE resulted in an increase in fasting TG which was likely due to a long fasting period and TG re-esterification following lipolysis $[35,39,40]$. It should be noted, however, that the benefits of TRE are minimal in patients with normal lipid levels and the benefits are more pronounced in those with elevated baseline lipids $[35,36]$.

\subsection{Neuroendocrine, Metabolic, Oxidative Stress, and Inflammation Biomarkers}

An impact of TRE on metabolic and neuroendocrine hormones in humans remains poorly investigated $[39,40,98]$. Early 6 -h TRE resulted in a decrease in morning and mean ghrelin levels and altered diurnal patterns in cortisol $[39,40]$.

Scant data about the impact of TRE on oxidative stress suggest a reduction of lipid peroxidation (lowering of 8-isoprostane levels by 14\%) in obese subjects including men with prediabetes, which may indicate that TRE potentially reduces a risk of atherosclerosis [35,42]. Importantly, both 4-h and 6-h TRE produced comparable reduction in 8-isoprostane levels (up to 37\%) in obese adults [42]. The decrease in oxidative stress may be related to improvements in insulin resistance. It has been demonstrated that insulin signaling is impaired during oxidative stress, resulting in insulin resistance of the cell [72,73]. Also, insulin sensitivity improves when administering antioxidants such as vitamin E [113].

Data on the effects of TRE on the inflammatory markers in humans are limited and inconsistent $[16,35,41,42,100]$. No significant improvement in high-sensitivity CRP level was detected in the pilot study of patients with MetS [16]. Also, TRE had no effect on circulating CRP, tumor necrosis factor- $\alpha$, and interleukin- 6 in obese subjects including men with prediabetes $[35,42]$. Altered expression of several circadian clock genes was reported post TRE in overweight and obese individuals $[39,43]$. There is some evidence that TRE may have a beneficial effect on the gut microbiome [18,114].

\subsection{Blood Pressure}

TRE resulted in a reduction of systolic (up to $\sim 5-11 \mathrm{mmHg}$ ) and diastolic (up to $\sim 7-10$ $\mathrm{mmHg}$ ) BP in a few studies of middle-aged obese subjects [36,44], patients with MetS [16] and obese adults with prediabetes, even in the absence of weight loss [35]. In patients with MetS, systolic and diastolic BP decreased by $\sim 4 \%$ and $8 \%$, respectively, which is comparable or even greater to that expected by weight loss through other means $[16,115]$. Large reductions in BP in the study of early TRE, which were comparable with the antihypertensive effects of angiotensin-converting enzyme inhibitors, may suggest that the improvements in $\mathrm{BP}$ were driven by the decrease in insulin levels and increased natriuresis by shifting salt intake to earlier in the daytime $[35,116,117]$. In addition, TRE can increase the efficacy of pharmacotherapy that also exhibits circadian rhythms [118]. However, no change in BP 
was observed in a few other studies of obese adults, so further evidence of the impact of TRE on BP is needed [42,44].

\subsection{Behavioral Effects and Safety}

Multiple beneficial behavioral outcomes of TRE were observed in various populations including patients with MetS, such as an improvement in self-reported sleep, energy level, subjective feeling of hunger at bedtime, quality of life and well-being [10,16,35,37-40,43,107]. Early 6-h TRE resulted in a decrease in appetite, and, despite the longer daily fasting duration, feeling of hunger in the evening, which may facilitate weight loss [35,40]. In the study of Ravussin et al. [40], the early TRE facilitated weight loss primarily by decreasing appetite rather than by increasing energy expenditure. Aligning food intake with circadian rhythms may, therefore, be a good strategy for reducing appetite and losing weight. Physical activity usually remained unchanged in TRE studies if participants were not instructed to change their habits regarding physical activity $[11,16]$. Work schedules, family commitments and social events have been considered as barriers to long-term implementation of TRE [43,47].

Self-reported adverse events (such as nausea, vomiting, headaches, dizziness, increased thirst, constipation, and diarrhea) were rare during TRE intervention [35,41] or no events were reported during 8-10-h TRE $[16,42,106]$. Importantly, TRE was safe even when short eating windows of 4 or $6 \mathrm{~h}$ were implemented [42]. The findings of previous TRE studies indicated that mild adverse effects may occur at the onset of TRE, but they usually disappear when the participant becomes adjusted to the diet [41,42].

\section{Effectiveness of TRE in Humans with MetS or Its Components: Summary of Clinical Evidence}

Patients with MetS have abnormal regulation of glucose and fat metabolism, increased inflammation and oxidative stress, and disrupted regulation of metabolic hormones. These changes lead to widespread chronic diseases from obesity, T2DM, to CVD. Previous TRE human studies provided the evidence that adopting a simple TRE pattern intervention is feasible and can lead to restoring rhythmic daily behavior resulting in a reduction of cardiometabolic risks and improvements of health in populations with metabolic disorders including patients with MetS (Figure 1).

Specifically, several small-scale studies in humans with metabolic disorders including one pilot study of patients with MetS showed that TRE resulted in weight loss and a decrease in eating window duration, fat mass, and energy intake, as well as improved glucose tolerance, insulin resistance, glycemic control, lipids, self-reported sleep, and reduced BP $[10,11,16,35-43,107]$. In the pilot study of an American population of patients with MetS, the improvements in body weight and fat, waist circumference, atherogenic lipids, and BP were observed despite no overt attempt to change diet quantity and quality or physical activity, and cardiometabolic benefits were mostly independent of change in body weight and eating window [16].

In the populations with central obesity, elevated BP and elevated FPG, TRE resulted in a decrease in weight, fasting glucose levels obtained by CGM, fasting TG, feeling of hunger, as well as improvements in glucose tolerance and quality of life [37,38]. In the populations with central obesity and elevated BP, TRE improved body weight and fat, fasting glucose levels obtained by CGM, insulin resistance, and oxidative stress [11,42]. Prediabetic and obese men who followed TRE intervention without losing weight exhibited improvements in insulin sensitivity, BP, oxidative stress, and reduced appetite [35]. TRE has been readily adoptable in the populations with central obesity and resulted in reducing body weight, waist circumference, feeling of hunger, ghrelin, systolic BP, and improvements in insulin resistance, glycemic control, oxidative stress, sleep, and well-being [10,36,39-41,43].

Obese adults with a prolonged daily eating window undergoing TRE intervention easily improved body weight and fat without calorie counting $[10,11,16]$. Moreover, TRE studies of subjects with metabolic disorders, mainly involving US populations, reported high patient adherence to TRE intervention which supports sustainability of this therapeutic approach, especially if it is monitored by using the mCC app $[10,11,16,35,36,38,44]$. 
Based on the current evidence provided by TRE studies of patients with metabolic disease, the American Heart Association published a scientific statement which supports the notion that maintaining a consistent eating period during the day and prolonged overnight fasting can mitigate cardiometabolic risks and prevent CVD [119].

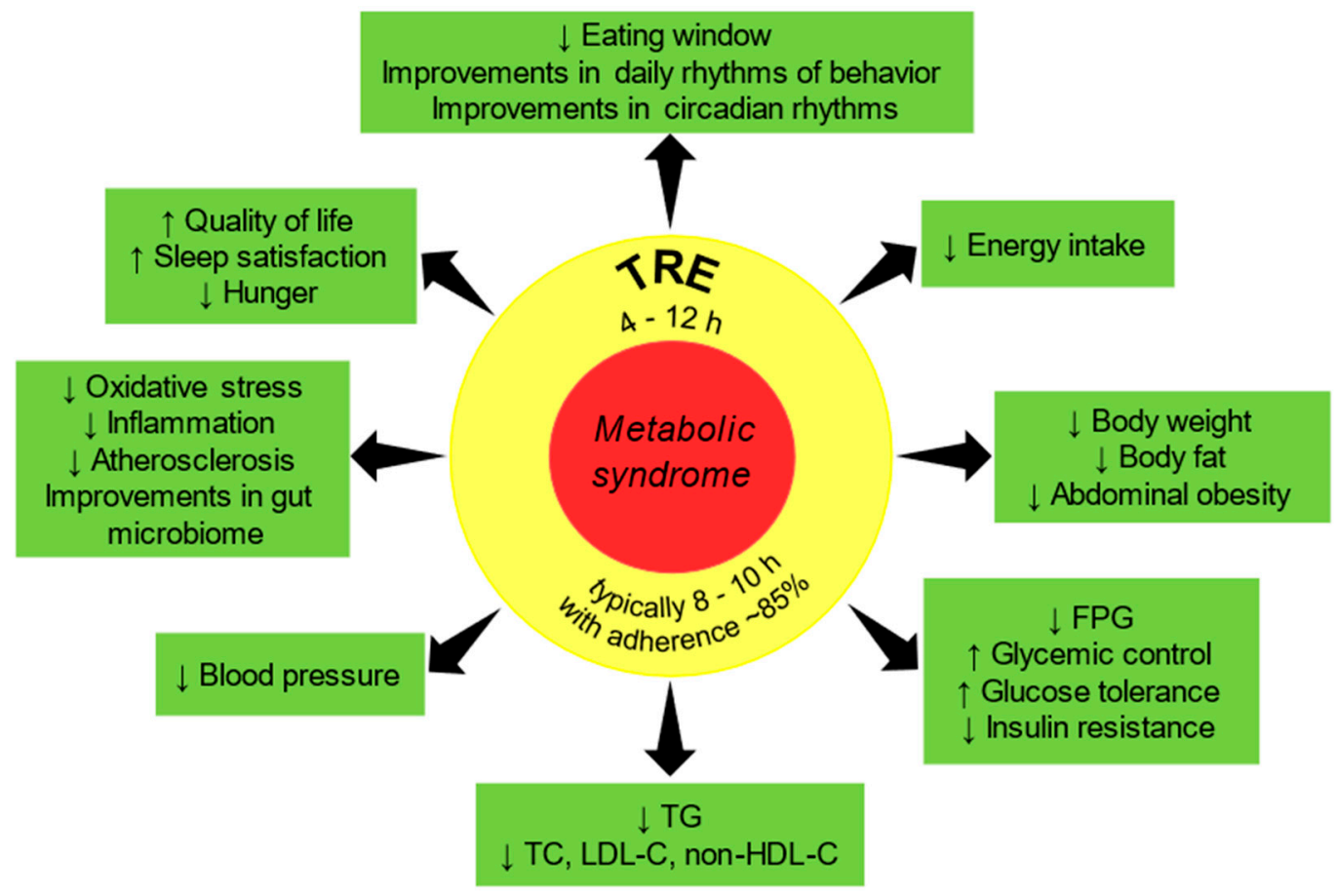

Figure 1. Demonstrated and potential cardiometabolic benefits of time-restricted eating (TRE). FPG: fasting plasma glucose; LDL-C: low-density lipoprotein cholesterol; non-HDL-C: non-high-density lipoprotein cholesterol; TC: total cholesterol: TG: triglycerides. The arrow pointing down indicates a decrease and the arrow pointing up indicates an increase.

\section{Knowledge Gaps and Future Perspectives for TRE in MetS}

TRE offers a promising strategy for the prevention and treatment of cardiometabolic disease including MetS. However, most TRE studies were focused on evaluating the feasibility and/or effects of TRE intervention in healthy individuals with normal weight and overweight or obese adults without overt metabolic disease. The in-depth interpretation and generalization of the effectiveness of TRE in MetS is hampered by several factors such as a limited number of TRE human studies, various populations, small sample size, short-term duration of TRE intervention and follow-up, various TRE eating windows implemented at different times during a day, and study design without non-TRE control group. While only one pilot TRE study (19 patients) provides results that are specific to an American population with diagnosed MetS [16], the findings of several other TRE studies that included individuals with one or more components of MetS suggest potential usefulness of TRE for improving the outcome of subjects with cardiometabolic disease.

Despite the encouraging results, various aspects associated with feasibility and effectiveness of TRE intervention, and sustainability of weight loss and cardiometabolic benefits long term in patients with MetS require further research. First, we recall that the enrollment criterion to target a population with diagnosed MetS has been uncommon in previous TRE studies. Also, a few TRE studies, including the pilot study of subjects with MetS, involved participants with a prolonged eating window $(\geq 14 \mathrm{~h})[10,11,16]$. Therefore, the findings of these studies may not be applicable to subjects with metabolic disease and shorter eating window. It appears that further clinical research including exclusively patients with diagnosed MetS regardless of baseline eating window is needed. Moreover, data on the feasibility and effectiveness of TRE in European populations with MetS or its components are presently very much limited [41]. 
Second, large-scale randomized controlled trials with longer duration of TRE intervention and long-term follow-up are desirable. Specifically, TRE trials with long intervention period ( $>12$ months) would be useful to test if a decrease in energy intake without calorie counting followed by weight loss, which was observed previously during shorter TRE interventions, persists and is sustainable long term. In addition, most previous TRE studies of individuals with metabolic disorders included midlife subjects while only a few trials involved young and older individuals [38-40]. Given a risk of age-related muscle loss, more evidence of TRE effects on nutrient intake, muscle strength and bone mineral density, especially in elderly populations, is desirable $[46,103,120]$. Modulating the gut microbiota through TRE to reverse microbial dysbiosis associated with circadian misalignment may mitigate metabolic risk [18,114], so the effects of TRE on the gut microbiome with potential benefit in MetS warrant further investigation.

Third, the effects of TRE on glucose and lipid metabolism were found to be highly variable in TRE studies of various populations with metabolic disorders. Specifically, the results of potentially unfavorable TRE effects on lipids require further investigation $[35,39,40]$. Also, the effects of TRE on metabolic and neuroendocrine homeostasis have been poorly investigated. Data on the effects of TRE on inflammatory markers in humans, including MetS patients, are limited and inconsistent. There are also only scant data about the impact of TRE on oxidative stress. Therefore, extending the protocols used in TRE studies by including more comprehensive range of biomarkers is needed.

Fourth, the optimal TRE eating duration and timing require special attention in further research. Beneficial effects of TRE were observed with various TRE protocols; however, it is likely that greater eating period restriction would produce more benefits [11,47]. On the other hand, while short eating windows could result in worsening of adherence and nutrient intake, extending the eating window beyond $12 \mathrm{~h}$ seems to produce no beneficial effects [98]. Available data seem to support a $10 \mathrm{~h}$ TRE eating window as this window still produces benefit and long-term adherence is better $[10,16]$. Also, more data to address the contribution of TRE timing (early vs. late eating) to the observed metabolic effects are needed. Although delayed TRE is likely more attractive and more amenable to long-term adherence, it might not be optimal for the metabolic advantages of TRE.

Finally, the mechanisms of beneficial effects of TRE in humans are still poorly understood. Importantly, measurement of circadian rhythms has not been performed in previous TRE human studies although it would be useful for understanding the mechanisms of TRE effects [17]. Extensions of study protocols with circadian rhythms measurements, mitochondrial function evaluation, and additional tools for recording food intake and chrono-nutrition assessment are desirable. Also, the roles of weight loss, energy restriction, decreasing appetite, delimitation of an eating window, changes in energy expenditure and caloric balance in beneficial metabolic effects of TRE require elucidation. Available data suggest that the benefits of TRE go beyond the benefits of caloric restriction and weight loss $[16,35]$.

The rationale for the extant TRE clinical human studies builds largely on extensive mechanistic molecular and physiological studies of circadian rhythms, eating patterns, and metabolic homeostasis, both in animal models and human studies. Although TRE is promising for prevention and treatment of cardiometabolic diseases, evidence of the effectiveness of TRE in MetS is limited, thus necessitating focused human studies. The extensions of study protocols are important to advance an understanding of the roles of metabolic regulatory mechanisms and circadian system in the pathophysiology of MetS and its complications. An important example of the paucity of information relates to the implementation and cardiometabolic effects of TRE as an alternative approach in the management of the European populations with MetS. Some new results are expected in the near future as indicated by the search of clinical trials registries, which shows that a few TRE studies in the European and American populations of patients with metabolic disorders including MetS and shift workers were recently undertaken [121]. The acquisition of TRE-related data for different populations and the use of consistent protocols would 
facilitate creation of joint databases and comparative analysis of patients with MetS from different countries and continents.

The TRE intervention represents an approach that can have translational impacts leading to improvements in health and a reduction of risks for cardiometabolic diseases, disability, and premature death. Projected short-term improvements include beneficial changes in body weight and composition, sleep and physical activity, performance and wellbeing. The findings of previous studies suggest that TRE is achievable and can help adults with obesity or other metabolic disorders to reduce calorie intake and lose weight without calorie counting, and improve cardiometabolic health. Future TRE studies are needed and would contribute to TRE research which can ultimately lead to the development of a circadian lifestyle management plan for patients with MetS, including dietary guidelines and nutritional and health policies towards alleviating health risks.

\section{Conclusions}

Sustaining a consistent daily rhythm of eating and fasting through implementing TRE in patients with MetS can aid in restoring robust circadian rhythms and improve metabolic regulatory mechanisms, which can favorably impact cardiometabolic health. The available findings of TRE human trials laid the groundwork and indicate a need for further clinical research including large-scale randomized controlled trials to determine the efficacy of TRE for reducing long-term cardiometabolic risk, providing tools for sustained lifestyle changes and, ultimately, improving overall health in patients with MetS.

Author Contributions: Conceptualization, I.Ś.; writing—original draft preparation, I.Ś.; writingreview and editing, I.Ś., A.W., and P.R.T.; visualization, I.S. and A.W. All authors have read and agreed to the published version of the manuscript.

Funding: This research received no external funding.

Data Availability Statement: Not applicable.

Acknowledgments: We thank two anonymous reviewers for valuable comments.

Conflicts of Interest: The authors declare no conflict of interest.

\section{References}

1. Scuteri, A.; Laurent, S.; Cucca, F.; Cockcroft, J.; Cunha, P.G.; Mañas, L.R.; Raso, F.U.M.; Muiesan, M.L.; Ryliškyte, L.; Rietzschel, E.; et al. Metabolic syndrome across Europe: Different clusters of risk factors. Eur. J. Prev. Cardiol. 2015, 22, 486-491. [CrossRef]

2. Virani, S.S.; Alonso, A.; Benjamin, E.J.; Bittencourt, M.S.; Callaway, C.W.; Carson, A.P.; Chamberlain, A.M.; Chang, A.R.; Cheng, S.; Delling, F.N.; et al. On behalf of the American Heart Association Council on Epidemiology and Prevention statistics committee and stroke statistics subcommittee. Heart disease and stroke statistics-2020 update: A report from the American Heart Association. Circulation 2020, 141, e139-e596.

3. Alberti, K.G.M.M.; Eckel, R.H.; Grundy, S.M.; Zimmet, P.Z.; Cleeman, J.I.; Donato, K.A.; Fruchart, J.C.; James, W.P.T.; Loria, C.M.; Smith, S.C., Jr.; et al. Harmonizing the metabolic syndrome: A joint interim statement of the International Diabetes Federation Task Force on Epidemiology and Prevention; National Heart, Lung, and Blood Institute; American Heart Association; World Heart Federation; International Atherosclerosis Society; and International Association for the Study of Obesity. Circulation 2009, 120, 1640-1645.

4. Sygnowska, E.; Piwońska, A.; Waśkiewicz, A.; Broda, G. Socioeconomic factors and the risk of metabolic syndrome in the adult Polish population: The WOBASZ study. Kardiol. Pol. 2012, 70, 718-727.

5. $\quad$ Eckel, R.H.; Alberti, K.G.M.M.; Grundy, S.M.; Zimmet, P.Z. The metabolic syndrome. Lancet 2010, 375, 181-183. [CrossRef]

6. Suliga, E.; Kozieł, D.; Cieśla, E.; Rebak, D.; Głuszek, S. Dietary patterns in relation to metabolic syndrome among adults in Poland: A Cross-sectional study. Nutrients 2017, 9, 1366. [CrossRef]

7. Kant, A.K.; Graubard, B.I. 40-year trends in meal and snack eating behaviors of American adults. J. Acad. Nutr. Diet. 2015, 115, 50-63. [CrossRef]

8. Riou, J.; Lefevre, T.; Parizot, I.; Lhuissier, A.; Chauvin, P. Is there still a French eating model? A taxonomy of eating behaviors in adults living in the Paris metropolitan area in 2010. PLoS ONE 2015, 10, e0119161.

9. Gupta, N.J.; Kumar, V.; Panda, S. A camera-phone based study reveals erratic eating pattern and disrupted daily eating-fasting cycle among adults in India. PLoS ONE 2017, 12, e0172852. 
10. Gill, S.; Panda, S. A Smartphone app reveals erratic diurnal eating patterns in humans that can be modulated for health benefits. Cell Metab. 2015, 22, 789-798. [CrossRef]

11. Chow, L.S.; Manoogian, E.N.C.; Alvear, A.; Fleischer, J.G.; Thor, H.; Dietsche, K.; Wang, Q.; Hodges, J.S.; Esch, N.; Malaeb, S.; et al. Time-restricted eating effects on body composition and metabolic measures in humans who are overweight: A feasibility study. Obesity 2020, 28, 860-869. [CrossRef] [PubMed]

12. Zarrinpar, A.; Chaix, A.; Panda, S. Daily eating patterns and their impact on health and disease. Trends Endocrinol. Metab. 2016, 27, 69-83. [CrossRef] [PubMed]

13. Cahill, L.E.; Chiuve, S.E.; Mekary, R.A.; Jensen, M.K.; Flint, A.J.; Hu, F.B.; Rimm, E.B. Prospective study of breakfast eating and incident coronary heart disease in a cohort of male US health professionals. Circulation 2013, 128, 337-343. [CrossRef] [PubMed]

14. Pot, G.K.; Almoosawi, S.; Stephen, A.M. Meal irregularity and cardiometabolic consequences: Results from observational and intervention studies. Proc. Nutr. Soc. 2016, 75, 475-486. [CrossRef]

15. Ha, K.; Song, Y. Associations of meal timing and frequency with obesity and metabolic syndrome among Korean adults. Nutrients 2019, 11, 2437. [CrossRef]

16. Wilkinson, M.J.; Manoogian, E.N.; Zadourian, A.; Lo, H.; Fakhouri, S.; Shoghi, A.; Wang, X.; Fleischer, J.G.; Navlakha, S.; Panda, S.; et al. Ten-hour time-restricted eating reduces weight, blood pressure, and atherogenic lipids in patients with metabolic syndrome. Cell Metab. 2020, 31, 92-104.e5. [CrossRef]

17. Xie, Y.; Tang, Q.; Chen, G.; Xie, M.; Yu, S.; Zhao, J.; Chen, L. New insights into the circadian rhythm and its related diseases. Front. Physiol. 2019, 10, 682. [CrossRef]

18. Chaix, A.; Manoogian, E.N.; Melkani, G.C.; Panda, S. Time-restricted eating to prevent and manage chronic metabolic diseases. Annu. Rev. Nutr. 2019, 39, 291-315. [CrossRef]

19. Mason, I.C.; Qian, J.; Adler, G.K.; Scheer, F.A.J.L. Impact of circadian disruption on glucose metabolism: Implications for type 2 diabetes. Diabetologia 2020, 63, 462-472. [CrossRef]

20. Stenvers, D.J.; Scheer, F.A.J.L.; Schrauwen, P.; La Fleur, S.E.; Kalsbeek, A. Circadian clocks and insulin resistance. Nat. Rev. Endocrinol. 2019, 15, 75-89. [CrossRef]

21. Chellappa, S.L.; Vujovic, N.; Williams, J.S.; Scheer, F.A.J.L. Impact of circadian disruption on cardiovascular function and disease Trends Endocrinol. Metab. 2019, 30, 767-779. [CrossRef] [PubMed]

22. Suliga, E.; Cieśla, E.; Rębak, D.; Kozieł, D.; Głuszek, S. Relationship between sitting time, physical activity, and metabolic syndrome among adults depending on body mass index (BMI). Med. Sci. Monit. 2018, 24, 7633-7645. [CrossRef] [PubMed]

23. Sperling, L.C.; Mechanick, J.I.; Neeland, I.J.; Herrick, C.J.; Després, J.P.; Ndumele, C.E.; Vijayaraghavan, K.; Handelsman, Y.; Puckrein, G.A.; Araneta, M.R.G.; et al. The CardioMetabolic Health Alliance. Working toward a new care model for the metabolic syndrome. Am. Coll. Cardiol. 2015, 66, 1050-1067. [CrossRef] [PubMed]

24. Vera, B.; Dashti, H.S.; Gómez-Abellán, P.; Hernández, A.M.; Esteban, A.; Scheer, F.A.J.L.; Saxena, R.; Garaulet, M. Modifiable lifestyle behaviors, but not a genetic risk score, associate with metabolic syndrome in evening chronotypes. Sci. Rep. 2018, 8, 945 [CrossRef] [PubMed]

25. Pérez-Martínez, P.; Mikhailidis, D.P.; Athyros, V.G.; Bullo, M.; Couture, P.; Covas, M.I.; de Koning, L.; Delgado-Lista, J.; DíazLópez, A.; Drevon, C.A.; et al. Lifestyle recommendations for the prevention and management of metabolic syndrome: An international panel recommendation. Nutr. Rev. 2017, 75, 307-326.

26. Heymsfield, S.B.; Harp, J.B.; Reitman, M.L.; Beetsch, J.W.; Schoeller, D.A.; Erondu, N.; Pietrobelli, A. Why do obese patients not lose more weight when treated with low-calorie diets? A mechanistic perspective. Am. J. Clin. Nutr. 2007, 85, 346-354. [CrossRef]

27. Feinman, R.D.; Pogozelski, W.K.; Astrup, A.; Bernstein, R.K.; Fine, E.J.; Westman, E.C.; Accurso, A.; Frassetto, L.; Gower, B.A.; McFarlane, S.I.; et al. Dietary carbohydrate restriction as the first approach in diabetes management: Critical review and evidence base. Nutrition 2015, 31, 1-13. [CrossRef]

28. Sulli, G.; Manoogian, E.N.; Taub, P.R.; Panda, S. Training the circadian clock, clocking the drugs, and drugging the clock to prevent, manage, and treat chronic diseases. Trends Pharmacol. Sci. 2018, 39, 812-827. [CrossRef]

29. Lopez-Minguez, J.; Gómez-Abellán, P.; Garaulet, M. Circadian rhythms, food timing and obesity. Proc. Nutr. Soc. 2016, 75, 501-511. [CrossRef]

30. De Cabo, R.; Mattson, M.P. Effects of intermittent fasting on health, aging, and disease. N. Engl. J. Med. 2019, 381, 2541-2551. [CrossRef]

31. Dashti, H.S.; Scheer, F.A.J.L.; Saxena, R.; Garaulet, M. Timing of food intake: Identifying contributing factors to design effective interventions. Adv. Nutr. 2019, 10, 606-620. [CrossRef] [PubMed]

32. Dong, T.A.; Sandesara, P.B.; Dhindsa, D.S.; Quyyumi, A.A.; Arneson, L.C.; Dollar, A.L.; Taub, P.R.; Sperling, L.S. Intermittent fasting: A heart healthy dietary pattern? Am. J. Med. 2020, 133, 901-907. [CrossRef] [PubMed]

33. Panda, S. Circadian physiology of metabolism. Science 2016, 354, 1008-1015. [CrossRef]

34. Antoni, R.; Robertson, T.M.; Robertson, M.D.; Johnston, J.D. A pilot feasibility study exploring the effects of a moderate timerestricted feeding intervention on energy intake, adiposity and metabolic physiology in free-living human subjects. J. Nutr. Sci. 2018, 7, 22. [CrossRef]

35. Sutton, E.F.; Beyl, R.; Early, K.S.; Cefalu, W.T.; Ravussin, E.; Peterson, C.M. Early time-restricted feeding improves insulin sensitivity, blood pressure, and oxidative stress even without weight loss in men with prediabetes. Cell Metab. 2018, 27, 1212-1221.e3. [CrossRef] 
36. Gabel, K.; Hoddy, K.K.; Haggerty, N.; Song, J.; Kroeger, C.M.; Trepanowski, J.F.; Panda, S.; Varady, K.A. Effects of 8-hour time restricted feeding on body weight and metabolic disease risk factors in obese adults: A pilot study. Nutr. Healthy Aging 2018, 4, 345-353. [CrossRef]

37. Hutchison, A.T.; Regmi, P.; Manoogian, E.N.; Fleischer, J.G.; Wittert, G.A.; Panda, S.; Heilbronn, L.K. Time-restricted feeding improves glucose tolerance in men at risk for type 2 diabetes: A randomized crossover trial. Obesity 2019, 27, 724-732. [CrossRef]

38. Anton, S.D.; Lee, S.A.; Donahoo, W.T.; McLaren, C.; Manini, T.M.; Leeuwenburgh, C.; Pahor, M. The effects of time restricted feeding on overweight, older adults: A Pilot Study. Nutrients 2019, 11, 1500. [CrossRef] [PubMed]

39. Jamshed, H.; Beyl, R.A.; Della Manna, D.L.; Yang, E.S.; Ravussin, E.; Peterson, C.M. Early Time-restricted feeding improves 24-hour glucose levels and affects markers of the circadian clock, aging, and autophagy in humans. Nutrients 2019, 11, 1234 [CrossRef]

40. Ravussin, E.; Beyl, R.A.; Poggiogalle, E.; Hsia, D.S.; Peterson, C.M. Early time-restricted feeding reduces appetite and increases fat oxidation but does not affect energy expenditure in humans. Obesity 2019, 27, 1244-1254. [CrossRef]

41. Kesztyüs, D.; Cermak, P.; Gulich, M.; Kesztyüs, T. Adherence to time-restricted feeding and impact on abdominal obesity in primary care patients: Results of a pilot study in a pre-post design. Nutrients 2019, 11, 2854. [CrossRef] [PubMed]

42. Cienfuegos, S.; Gabel, K.; Kalam, F.; Ezpeleta, M.; Wiseman, E.; Pavlou, V.; Lin, S.; Oliveira, M.L.; Varady, K.A. Effects of 4- and 6-h time-restricted feeding on weight and cardiometabolic health: A randomized controlled trial in adults with obesity. Cell Metab. 2020, 32, 366-378.e3. [CrossRef]

43. Parr, E.B.; Devlin, B.L.; Radford, B.E.; Hawley, J.A. A delayed morning and earlier evening time-restricted feeding protocol for improving glycemic control and dietary adherence in men with overweight/obesity: A randomized controlled trial. Nutrients 2020, 12, 505. [CrossRef]

44. Lowe, D.A.; Wu, N.; Rohdin-Bibby, L.; Moore, A.H.; Kelly, N.; Liu, Y.E.; Philip, E.; Vittinghoff, E.; Heymsfield, S.B.; Olgin, J.E.; et al. Effects of time-restricted eating on weight loss and other metabolic parameters in women and men with overweight and obesity. JAMA Intern. Med. 2020, 180, 1491. [CrossRef] [PubMed]

45. Moon, S.; Kang, J.; Kim, S.H.; Chung, H.S.; Kim, Y.J.; Yu, J.M.; Cho, S.T.; Oh, C.-M.; Kim, T. Beneficial effects of time-restricted eating on metabolic diseases: A systemic review and meta-analysis. Nutrients 2020, 12, 1267. [CrossRef]

46. Queiroz, J.D.N.; Macedo, R.C.; Tinsley, G.M.; Reischak-Oliveira, A. Time-restricted eating and circadian rhythms: The biological clock is ticking. Crit. Rev. Food Sci. Nutr. 2020, 14, 1-13. [CrossRef]

47. Regmi, P.; Heilbronn, L.K. Time-restricted eating: Benefits, mechanisms, and challenges in translation. iScience 2020, $23,101161$. [CrossRef]

48. International Diabetes Federation. Consensus Statements-IDF Consensus Worldwide Definition of the Metabolic Syndrome. Available online: https: / www.idf.org/e-library / consensus-statements / 60-idfconsensus-worldwide-definitionof-the-metabolicsyndrome.html (accessed on 29 November 2020).

49. The GBD 2015 Obesity Collaborators. Health effects of overweight and obesity in 195 countries over 25 years. N. Engl. J. Med. 2017, 377, 13-27.

50. Ervin, R.B. Prevalence of metabolic syndrome among adults 20 years of age and over, by sex, age, race and ethnicity, and body mass index: United States, 2003-2006. Natl. Heal. Stat. Rep. 2009, 5, 1-7.

51. Głuszek, S.; Ciesla, E.; Głuszek-Osuch, M.; Kozieł, D.; Kiebzak, W.; Wypchło, Ł.; Suliga, E. Anthropometric indices and cut-off points in the diagnosis of metabolic disorders. PLoS ONE 2020, 15, e0235121. [CrossRef]

52. Suliga, E.; Kozieł, D.; Głuszek, S. Prevalence of metabolic syndrome in normal weight individuals. Ann. Agric. Environ. Med. 2016, 23, 631-635. [CrossRef]

53. Bays, H.E.; Toth, P.P.; Kris-Etherton, P.M.; Abate, N.; Aronne, L.J.; Brown, W.V.; Gonzalez-Campoy, J.M.; Jones, S.R.; Kumar, R.; La Forge, R.; et al. Obesity, adiposity, and dyslipidemia: A consensus statement from the National Lipid Association. J. Clin. Lipidol. 2013, 7, 304-383. [CrossRef]

54. Beltrán-Sánchez, H.; Harhay, M.O.; Harhay, M.M.; McElligott, S. Prevalence and trends of metabolic syndrome in the adult U.S. population, 1999-2010. J. Am. Coll. Cardiol. 2013, 62, 697-703. [CrossRef]

55. Efeyan, A.; Comb, W.C.; Sabatini, D.M. Nutrient-sensing mechanisms and pathways. Nature 2015, 517, 302-310. [CrossRef]

56. Maury, E.; Ramsey, K.M.; Bass, J. Circadian rhythms and metabolic syndrome: From experimental genetics to human disease. Circ. Res. 2010, 106, 447-462. [CrossRef]

57. Szewczyk-Golec, K.; Woźniak, A.; Reiter, R.A. Inter-relationship of the chronobiotic, melatonin, with leptin and adiponectin: Implications for obesity. J. Pineal Res. 2015, 59, 277-291. [CrossRef]

58. Szewczyk-Golec, K.; Rajewski, P.; Gackowski, M.; Mila-Kierzenkowska, C.; Wesołowski, R.; Sutkowy, P.; Pawłowska, M.; Woźniak, A. Melatonin supplementation lowers oxidative stress and regulates adipokines in obese patients on a calorie-restricted diet. Oxid. Med. Cell Longev. 2017, 2017, 8494107. [CrossRef]

59. Qian, J.; Morris, C.J.; Caputo, R.; Garaulet, M.; Scheer, F.A.J.L. Ghrelin is impacted by the endogenous circadian system and by circadian misalignment in humans. Int. J. Obes. 2019, 43, 1644-1649. [CrossRef]

60. Garaulet, M.; Qian, J.; Florez, J.C.; Arendt, J.; Saxena, R.; Scheer, F.A.J.L. Melatonin effects on glucose metabolism: Time to unlock the controversy. Trends Endocrinol. Metab. 2020, 31, 192-204. [CrossRef]

61. Steppan, C.M.; Bailey, S.T.; Bhat, S.; Brown, E.J.; Banerjee, R.R.; Wright, C.M.; Patel, H.R.; Ahima, R.S.; Lazar, M.A. The hormone resistin links obesity to diabetes. Nature 2001, 409, 307-312. [CrossRef] 
62. Park, H.K.; Kwak, M.K.; Kim, H.J.; Ahima, R.S. Linking resistin, inflammation, and cardiometabolic diseases. Korean J. Intern. Med. 2017, 32, 239-247. [CrossRef] [PubMed]

63. Rutter, M.; Meigs, J.B.; Sullivan, L.M.; D’Agostino, R.B.; Wilson, P.W. C-reactive protein, the metabolic syndrome, and prediction of cardiovascular events in the framingham offspring study. Circulation 2004, 110, 380-385. [CrossRef] [PubMed]

64. Robertsa, C.K.; Sindhu, K.K. Oxidative stress and metabolic syndrome. Life Sci. 2009, 84, 705-712. [CrossRef] [PubMed]

65. Han, T.S.; Sattar, N.; Williams, K.; Gonzalez-Villalpando, C.; Lean, M.E.; Haffner, S.M. Prospective study of C-reactive protein in relation to the development of diabetes and metabolic syndrome in the Mexico City diabetes study. Diabetes Care 2002, 25, 2016-2021. [CrossRef] [PubMed]

66. Sattar, N.; Gaw, A.; Scherbakova, O.; Ford, I.; O’Reilly, D.S.; Haffner, S.M.; Isles, C.; Macfarlane, P.W.; Packard, C.J.; Cobbe, S.M.; et al. Metabolic syndrome with and without C-reactive protein as a predictor of coronary heart disease and diabetes in the West of Scotland coronary prevention study. Circulation 2003, 108, 414-419. [CrossRef]

67. Malik, S.; Wong, N.D.; Franklin, S.; Pio, J.; Fairchild, C.; Chen, R. Cardiovascular disease in U.S. patients with metabolic syndrome, diabetes, and elevated C-reactive protein. Diabetes Care 2005, 28, 690-693. [CrossRef]

68. Swiatkiewicz, I.; Taub, P.R. The usefulness of C-reactive protein for the prediction of post-infarct left ventricular systolic dysfunction and heart failure. Kardiol. Pol. 2018, 76, 821-829. [CrossRef]

69. Swiatkiewicz, I.; Magielski, P.; Kubica, A.; Zadourian, A.; DeMaria, A.N.; Taub, P.R. Enhanced inflammation is a marker for risk of post-infarct ventricular dysfunction and heart failure. Int. J. Mol. Sci. 2020, 21, 807. [CrossRef]

70. Aronson, D.; Bartha, P.; Zinder, O.; Kerner, A.; Markiewicz, W.; Avizohar, O.; Brook, G.J.; Levy, Y. Obesity is the major determinant of elevated C-reactive protein in subjects with the metabolic syndrome. Int. J. Obes. 2004, 28, 674-679. [CrossRef]

71. Aronson, D.; Sella, R.; Sheikh-Ahmad, M.; Kerner, A.; Avizohar, O.; Rispler, S.; Bartha, P.; Markiewicz, W.; Levy, Y.; Brook, G.J. The association between cardiorespiratory fitness and C-reactive protein in subjects with the metabolic syndrome. J. Am. Coll. Cardiol. 2004, 44, 2003-2007. [CrossRef]

72. Houstis, N.; Rosen, E.D.; Lander, E.S. Reactive oxygen species have a causal role in multiple forms of insulin resistance. Nature 2006, 440, 944-948. [CrossRef]

73. Rains, J.L.; Jain, S.K. Oxidative stress, insulin signaling, and diabetes. Free Radic. Biol. Med. 2011, 50, 567-575. [CrossRef]

74. Rania, V.; Deepb, G.; Singhc, R.K.; Palled, K.; Yadav, U.C.S. Oxidative stress and metabolic disorders: Pathogenesis and therapeutic strategies. Life Sci. 2016, 148, 183-193. [CrossRef] [PubMed]

75. Bass, J. Circadian topology of metabolism. Nature 2012, 491, 348-356. [CrossRef] [PubMed]

76. Asher, G.; Sassone-Corsi, P. Time for food: The intimate interplay between nutrition, metabolism, and the circadian clock. Cell 2015, 161, 84-92. [CrossRef] [PubMed]

77. Scheer, F.A.J.L.; Hu, K.; Evoniuk, H.; Kelly, E.E.; Malhotra, A.; Hilton, M.F.; Shea, S.A. Impact of the human circadian system, exercise, and their interaction on cardiovascular function. Proc. Natl. Acad. Sci. USA 2010, 107, 20541-20546. [CrossRef] [PubMed]

78. Qian, J.; Scheer, F.A.J.L. Circadian system and glucose metabolism: Implications for physiology and disease. Trends Endocrinol. Metab. 2016, 27, 282-293. [CrossRef] [PubMed]

79. Mattis, J.; Sehgal, A. Circadian rhythms, sleep, and disorders of aging. Trends Endocrinol. Metab. 2016, 27, 192-203. [CrossRef] [PubMed]

80. Vollmers, C.; Gill, S.; DiTacchio, L.; Pulivarthy, S.R.; Le, H.D.; Panda, S. Time of feeding and the intrinsic circadian clock drive rhythms in hepatic gene expression. Proc. Natl. Acad. Sci. USA 2009, 106, 21453-21458. [CrossRef]

81. Mattson, M.P.; Allison, D.B.; Fontana, L.; Harvie, M.; Longo, V.D.; Malaisse, W.J.; Mosley, M.; Notterpek, L.; Ravussin, E.; Scheer, F.A.J.L.; et al. Meal frequency and timing in health and disease. Proc. Natl. Acad. Sci. USA 2014, 111, 16647-16653. [CrossRef]

82. Scheer, F.A.J.L.; Hilton, M.F.; Mantzoros, C.S.; Shea, S.A. Adverse metabolic and cardiovascular consequences of circadian misalignment. Proc. Natl. Acad. Sci. USA 2009, 106, 4453-4458. [CrossRef] [PubMed]

83. Garaulet, M.; Gómez-Abellán, P.; Alburquerque-Béjar, J.J.; Lee, Y.-C.; Ordovás, J.M.; Scheer, F.A.J.L. Timing of food intake predicts weight loss effectiveness. Int. J. Obes. 2013, 37, 604-611. [CrossRef] [PubMed]

84. McHill, A.W.; Wright, K.P. Role of sleep and circadian disruption on energy expenditure and in metabolic predisposition to human obesity and metabolic disease. Obes. Rev. 2017, 18, 15-24. [CrossRef] [PubMed]

85. Kohsaka, A.; Laposky, A.; Ramsey, K.M.; Estrada, C.; Joshu, C.; Kobayashi, Y.; Turek, F.W.; Bass, J. High-fat diet disrupts behavioral and molecular circadian rhythms in mice. Cell Metab. 2007, 6, 414-421. [CrossRef] [PubMed]

86. Collet, T.-H.; van der Klaauw, A.A.; Henning, E.; Keogh, J.M.; Suddaby, D.; Dachi, S.V.; Dunbar, S.; Kelway, S.; Dickson, S.L.; Farooqi, I.S.; et al. The sleep/wake cycle is directly modulated by changes in energy balance. Sleep 2016, 39, 1691-1700. [CrossRef] [PubMed]

87. Puttonen, S.; Härmä, M.; Hublin, C. Shift work and cardiovascular disease-Pathways from circadian stress to morbidity. Scand. J. Work. Environ. Health 2010, 36, 96-108. [CrossRef]

88. McHill, A.W.; Melanson, E.L.; Higgins, J.; Connick, E.; Moehlman, T.M.; Stothard, E.R.; Wright, K.P. Impact of circadian misalignment on energy metabolism during simulated nightshift work. Proc. Natl. Acad. Sci. USA 2014, 111, 17302-17307. [CrossRef] 
89. Mukherji, A.; Kobiita, A.; Damara, M.; Misra, N.; Meziane, H.; Champy, M.-F.; Giangrande, A. Shifting eating to the circadian rest phase misaligns the peripheral clocks with the master SCN clock and leads to a metabolic syndrome. Proc. Natl. Acad. Sci. USA 2015, 112, E6691-E6698. [CrossRef]

90. Mohebbi, I.; Shateri, K.; Seyedmohammadzad, M. The relationship between working schedule patterns and the markers of the metabolic syndrome: Comparison of shift workers with day workers. Int. J. Occup. Med. Environ. Health 2012, 25, 383-391. [CrossRef]

91. Hall, M.H.; Muldoon, M.F.; Jennings, J.R.; Buysse, D.J.; Flory, J.D.; Manuck, S.B. Self-reported sleep duration is associated with the metabolic syndrome in midlife adults. Sleep 2008, 31, 635-643. [CrossRef]

92. Markwald, R.R.; Melanson, E.L.; Smith, M.R.; Higgins, J.; Perreault, L.; Eckel, R.H.; Wright, K.P. Impact of insufficient sleep on total daily energy expenditure, food intake, and weight gain. Proc. Natl. Acad. Sci. USA 2013, 110, 5695-5700. [CrossRef] [PubMed]

93. Hatori, M.; Vollmers, C.; Zarrinpar, A.; DiTacchio, L.; Bushong, E.A.; Gill, S.; Leblanc, M.; Chaix, A.; Joens, M.; Fitzpatrick, J.A.J.; et al. Time-restricted feeding without reducing caloric intake prevents metabolic diseases in mice fed a high-fat diet. Cell Metab. 2012, 15, 848-860. [CrossRef]

94. Chaix, A.; Zarrinpar, A.; Miu, P.; Panda, S. Time-restricted feeding is a preventative and therapeutic intervention against diverse nutritional challenges. Cell Metab. 2014, 20, 991-1005. [CrossRef]

95. Zarrinpar, A.; Chaix, A.; Yooseph, S.; Panda, S. Diet and feeding pattern affect the diurnal dynamics of the gut microbiome. Cell Metab. 2014, 20, 1006-1017. [CrossRef]

96. Chung, H.; Chou, W.; Sears, D.D.; Patterson, R.E.; Webster, N.J.; Ellies, L.G. Time-restricted feeding improves insulin resistance and hepatic steatosis in a mouse model of postmenopausal obesity. Metabolism 2016, 65, 1743-1754. [CrossRef] [PubMed]

97. Gill, S.; Le, H.D.; Melkani, G.C.; Panda, S. Time-restricted feeding attenuates age-related cardiac decline in Drosophila. Science 2015, 347, 1265-1269. [CrossRef]

98. LeCheminant, J.D.; Christenson, E.; Bailey, B.W.; Tucker, L.A. Restricting night-time eating reduces daily energy intake in healthy young men: A short-term cross-over study. Br. J. Nutr. 2013, 110, 2108-2113. [CrossRef]

99. McAllister, M.J.; Pigg, B.L.; Renteria, L.I.; Waldman, H.S. Time-restricted feeding improves markers of cardiometabolic health in physically active college-age men: A 4-week randomized pre-post pilot study. Nutr. Res. 2020, 75, 32-43. [CrossRef] [PubMed]

100. Moro, T.; Tinsley, G.; Bianco, A.; Marcolin, G.; Pacelli, Q.F.; Battaglia, G.; Palma, A.; Gentil, P.; Neri, M.; Paoli, A. Effects of eight weeks of time-restricted feeding (16/8) on basal metabolism, maximal strength, body composition, inflammation, and cardiovascular risk factors in resistance-trained males. J. Transl. Med. 2016, 14, 290. [CrossRef] [PubMed]

101. Tinsley, G.M.; Forsse, J.S.; Butler, N.K.; Paoli, A.; Bane, A.A.; La Bounty, P.M.; Morgan, G.B.; Grandjean, P.W. Time-restricted feeding in young men performing resistance training: A randomized controlled trial. Eur. J. Sport Sci. 2017, 17, 200-207. [CrossRef] [PubMed]

102. Tinsley, G.M.; Moore, M.L.; Graybeal, A.J.; Paoli, A.; Kim, Y.; Gonzales, J.U.; Harry, J.R.; VanDusseldorp, T.A.; Kennedy, D.N.; Cruz, M.R. Time-restricted feeding plus resistance training in active females: A randomized trial. Am. J. Clin. Nutr. 2019, 110, 628-640. [CrossRef]

103. Carlson, O.; Martin, B.; Stote, K.S.; Golden, E.; Maudsley, S.; Najjar, S.S.; Ferrucci, L.; Ingram, D.K.; Longo, D.L.; Rumpler, W.V.; et al. Impact of reduced meal frequency without caloric restriction on glucose regulation in healthy, normal-weight middle-aged men and women. Metabolism 2007, 56, 1729-1734. [CrossRef] [PubMed]

104. Stote, K.S.; Baer, D.J.; Spears, K.; Paul, D.R.; Harris, G.K.; Rumpler, W.V.; Strycula, P.; Najjar, S.S.; Ferrucci, L.; Ingram, D.K.; et al. A controlled trial of reduced meal frequency without caloric restriction in healthy, normal-weight, middle-aged adults. Am. $J$. Clin. Nutr. 2007, 85, 981-988. [CrossRef] [PubMed]

105. Martens, C.R.; Rossman, M.J.; Mazzo, M.R.; Jankowski, L.R.; Nagy, E.E.; Denman, B.A.; Richey, J.J.; Johnson, S.A.; Ziemba, B.P.; Wang, Y.; et al. Short-term time-restricted feeding is safe and feasible in non-obese healthy midlife and older adults. Geroscience 2020, 42, 667-686. [CrossRef] [PubMed]

106. Gabel, K.; Hoddy, K.K.; Varady, K.A. Safety of 8-h time restricted feeding in adults with obesity. Appl. Physiol. Nutr. Metab. 2019, 44, 107-109. [CrossRef] [PubMed]

107. Gabel, K.; Hoddy, K.K.; Burgess, H.J.; Varady, K.A. Effect of 8-h time-restricted feeding on sleep quality and duration in adults with obesity. Appl. Physiol. Nutr. Metab. 2019, 44, 903-906. [CrossRef] [PubMed]

108. Goris, A.H.C.; Westerterp-Plantenga, M.S.; Westerterp, K.R. Undereating and underrecording of habitual food intake in obese men: Selective underreporting of fat intake. Am. J. Clin. Nutr. 2000, 71, 130-134. [CrossRef]

109. Kubica, A.; Kasprzak, M.; Fabiszak, T.; Laskowska, E.; Navarese, E.P.; Sztuba, B.; Swiatkiewicz, I.; Kubica, J.; Obonska, K.; Kozinski, M.; et al. Discrepancies in assessment of adherence to antiplatelet treatment after myocardial infarction. Pharmacology 2015, 95, 50-58. [CrossRef]

110. Ackermann, R.T.; Liss, D.T.; Finch, E.A.; Schmidt, K.K.; Hays, L.M.; Marrero, D.G.; Saha, C. A randomized comparative effectiveness trial for preventing type 2 diabetes. Am. J. Public Health 2015, 105, 2328-2334. [CrossRef]

111. Katula, J.A.; Vitolins, M.Z.; Morgan, T.M.; Lawlor, M.S.; Blackwell, C.S.; Isom, S.P.; Pedley, C.F.; Goff, D.C. The healthy living partnerships to prevent diabetes study: 2-year outcomes of a randomized controlled trial. Am. J. Prev. Med. 2013, 44, S324-S332. [CrossRef] 
112. Jacobson, T.A.; Maki, K.C.; Orringer, C.E.; Jones, P.H.; Krisetherton, P.M.; Sikand, G.; La Forge, R.; Daniels, S.R.; Wilson, D.P.; Morris, P.B.; et al. National Lipid Association recommendations for patient-centered management of dyslipidemia: Part 2. J. Clin. Lipidol. 2015, 9, S1-S122.e1. [CrossRef] [PubMed]

113. Zaulkffali, A.S.; Md Razip, N.N.; Syed Alwi, S.S.; Abd Jalil, A.; Abd Mutalib, M.S.; Gopalsamy, B.; Chang, S.K.; Zainal, Z.; Ibrahim, N.N.; Zakaria, Z.A. Vitamins D and E stimulate the PI3K-AKT signalling pathway in insulin-resistant SK-N-SH neuronal cells. Nutrients 2019, 11, 2525. [CrossRef] [PubMed]

114. Zeb, F.; Wu, X.; Chen, L.; Fatima, S.; Haq, I.-U.; Chen, A.; Majeed, F.; Feng, Q.; Li, M. Effect of time-restricted feeding on metabolic risk and circadian rhythm associated with gut microbiome in healthy males. Br. J. Nutr. 2020, 123, 1216-1226. [CrossRef] [PubMed]

115. Zomer, E.; Gurusamy, K.; Leach, R.; Trimmer, C.; Lobstein, T.; Morris, S.; James, W.; Finer, N. Interventions that cause weight loss and the impact on cardiovascular risk factors: A systematic review and meta-analysis. Obes. Rev. 2016, 17, 1001-1011. [CrossRef]

116. Heran, B.S.; Galm, B.P.; Wright, J.M. Blood pressure lowering efficacy of alpha blockers for primary hypertension. Cochrane Database Syst. Rev. 2012, 7, CD004643. [CrossRef]

117. Johnston, J.G.; Speed, J.S.; Jin, C.; Pollock, D.M. Loss of endothelin B receptor function impairs sodium excretion in a time- and sex-dependent manner. Am. J. Physiol. Physiol. 2016, 311, F991-F998. [CrossRef]

118. Cederroth, C.R.; Albrecht, U.; Bass, J.; Brown, S.A.; Dyhrfjeld-Johnsen, J.; Gachon, F.; Green, C.B.; Hastings, M.H.; Helfrich-Förster, C.; HogenEsch, J.B.; et al. Medicine in the fourth dimension. Cell Metab. 2019, 30, 238-250. [CrossRef]

119. St-Onge, M.-P.; Jamy American Heart Association Obesity Committee of the Council on Lifestyle and Cardiometabolic Health; Council on Cardiovascular Disease in the Young; Council on Clinical Cardiology; Stroke Council; Baskin, M.L.; Chiuve, S.E.; Johnson, H.M.; Kris-Etherton, P.; Varady, K. Meal timing and frequency: Implications for cardiovascular disease prevention: A scientific statement from the American heart association. Circulation 2017, 135, e96-e121. [CrossRef]

120. Tinsley, G.M.; Paoli, A. Time-restricted eating and age-related muscle loss. Aging 2019, 11, 8741-8742. [CrossRef]

121. Quist, J.S.; Jensen, M.M.; Clemmensen, K.K.B.; Pedersen, H.; Bjerre, N.; Størling, J.; Blond, M.B.; Albrechtsen, N.W.; Holst, J.J.; Torekov, S.S.; et al. Protocol for a single-centre, parallel-group, randomised, controlled, superiority trial on the effects of timerestricted eating on body weight, behaviour and metabolism in individuals at high risk of type 2 diabetes: The REStricted Eating Time (RESET) study. BMJ Open 2020, 10, e037166. [CrossRef] 